\title{
Does the pension system's income statement really matter? A proposal for an NDC scheme with disability and minimum pension benefits
}

Complutense de Análisis Económico

\author{
Anne M. Garvey \\ Department of Economics and Management Sciences \\ University of Alcalá, Spain
}

\section{Manuel Ventura-Marco}

Department of Financial Economics and Actuarial Science

University of Valencia, Spain

\section{Carlos Vidal-Meliá}

Department of Financial Economics and Actuarial Science

University of Valencia (Spain) and

research affiliation with the Instituto Complutense de Análisis Económico (ICAE), Complutense University of Madrid (Spain) and the Centre of Excellence in Population Ageing Research (CEPAR), UNSW (Australia)

\begin{abstract}
This paper develops a full accounting model for monitoring the solvency of a notional defined contribution (NDC) pension scheme with disability and minimum pension benefits. Using the annual report of the Swedish pension system as a benchmark (TSPS, 2018), we extend the "Swedish" actuarial balance developed by Pérez-Salamero et al. (2017) by adding an income statement which fully explains the reasons behind the changes in the system's solvency by type of benefit. In line with the reference model, assets and liabilities are measured at present value at each reporting date, and changes in present value are reported in each period as income or expenses and are included on the income statement. Our proposed model is a step forward because it, also, incorporates the changes for disability pensions, the value of change in the discount rate and the explicit recognition of non-contributory rights (NCRs) into the Income statement. This accounting framework integrates both contributory and social aspects of public pensions and discloses the real cost of the disability contingency and the redistribution through minimum pensions. The paper contains a numerical example consisting of an income statement for a (fictional) already-functioning system to illustrate the main differences between the Swedish NDC scheme and our model. Mathematical details are presented in a comprehensive technical appendix.
\end{abstract}

Keywords Disability Insurance, Fair Presentation, Minimum Pensions, Notional Defined Contribution, Pay-as-you-go, Pension Accounting, Retirement, Sweden, True and Fair view.

JEL Classification $\quad$ G22, H55, H83, J26, M48

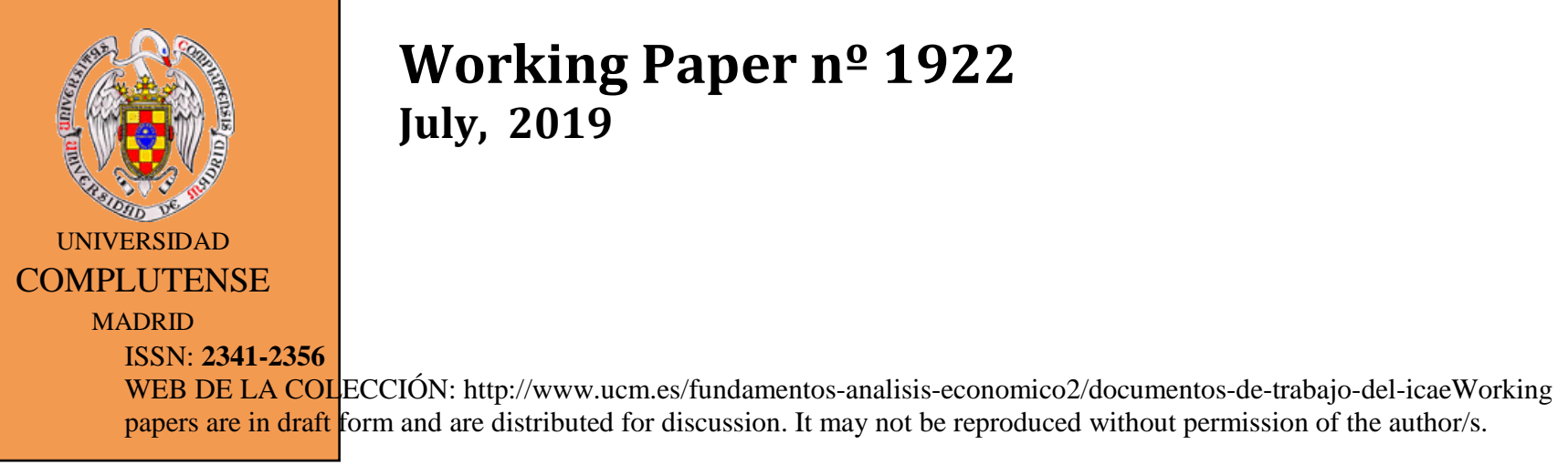

\section{Working Paper no 1922 \\ July, 2019}




\title{
Does the pension system's income statement really matter? A proposal for an NDC scheme with disability and minimum pension benefits*.
}

\author{
Anne M. Garvey , Manuel Ventura-Marco* and Carlos Vidal-Meliá * \\ $\square 05 / 07 / 2019$
}

\begin{abstract}
:
This paper develops a full accounting model for monitoring the solvency of a notional defined contribution (NDC) pension scheme with disability and minimum pension benefits. Using the annual report of the Swedish pension system as a benchmark (TSPS, 2018), we extend the "Swedish" actuarial balance developed by Pérez-Salamero et al. (2017) by adding an income statement which fully explains the reasons behind the changes in the system's solvency by type of benefit. In line with the reference model, assets and liabilities are measured at present value at each reporting date, and changes in present value are reported in each period as income or expenses and are included on the income statement. Our proposed model is a step forward because it, also, incorporates the changes for disability pensions, the value of change in the discount rate and the explicit recognition of non-contributory rights (NCRs) into the Income statement. This accounting framework integrates both contributory and social aspects of public pensions and discloses the real cost of the disability contingency and the redistribution through minimum pensions. The paper contains a numerical example consisting of an income statement for a (fictional) already-functioning system to illustrate the main differences between the Swedish NDC scheme and our model. Mathematical details are presented in a comprehensive technical appendix.
\end{abstract}

JEL: G22, H55, H83, J26, M48

KEYWORDS: Disability Insurance, Fair Presentation, Minimum Pensions, Notional Defined Contribution, Pay-as-you-go, Pension Accounting, Retirement, Sweden, True and Fair view.

\footnotetext{
* Manuel Ventura-Marco and Carlos Vidal-Meliá are grateful for the financial assistance received from the Spanish Ministry of the Economy and Competitiveness (Ministerio de Economía y Competitividad) project ECO2015-65826-P. Carlos Vidal-Meliá also acknowledges the financial support from the Basque Government (Project IT1336-19). Anne M. Garvey is grateful for the financial assistance received from the Spanish Ministry of the Economy and Competitiveness (Ministerio de Economía y Competitividad) project DER2015-67918-P and project CCG2018/HUM-017 from the University of Alcalá.

-Department of Economics and Management Sciences, University of Alcalá, (Spain) (e-mail: anne.garvey@uah.es)

- Department of Financial Economics and Actuarial Science, University of Valencia, Avenida de los Naranjos s.n., 46022 Valencia. (Spain). (e-mail: manuel.ventura@uv.es).

- Department of Financial Economics and Actuarial Science, University of Valencia (Spain) and research affiliation with the Instituto Complutense de Análisis Económico (ICAE), Complutense University of Madrid (Spain) and the Centre of Excellence in Population Ageing Research (CEPAR), UNSW (Australia). (e-mail: carlos.vidal@uv.es). (Corresponding author).
} 


\section{1.-INTRODUCTION}

The delivery or payment of social benefits to beneficiaries is one of the primary objectives of most governments and it accounts for a large proportion of their expenditure. In most countries, mandatory spending ${ }^{1}$ rises with the number of eligible beneficiaries (mainly due to population ageing) and prices. These increases are included without any further action by the governments ${ }^{2}$. Cost estimates of deferred payment programs are especially susceptible to misstatement in cash-basis budgetary accounting systems (Phaup, 2019).

It is important that the financial statements report the pension disbursements, and any associated liabilities, appropriately (Mason, 2018). The financial reporting method used for most of the social security systems (SSSs) around the world is based exclusively on cash accounting (see appendix 1) which is not a suitable framework for accounting for the assets and liabilities allocated to pay for the scheduled benefits. Reporting should be based mainly on the accrual accounting principle (see appendix 1), the fundamental cornerstone of good financial management.

Many countries have adopted the accrual accounting principle in the wave of "New Public Management reform" which considers the implementation of this methodology as a tool to gain wider accountability; to demonstrate that resources are used economically, efficiently, and effectively and as intended; to demonstrate value for money; to assess solvency and sustainability; to determine the costs of public services; to enhance monitoring of liabilities and contingent liabilities; and to record the complete stock of assets and liabilities (see appendix 1), in balance sheets (Cavanagh et al., 2016; Dabbicco, 2015; IMF, 2014).

Employment-related pension programs for non-public-sector employees are often required to be fully funded under national laws. In these benefit plans, liabilities and contribution requirements are normally determined based on standard actuarial techniques. As a result of a change in accounting standards over the past 25 years, these firms are required to include unfunded pension liabilities in their corporate balance sheets. If assets equal or exceed accrued liabilities, the plan is considered to be fully funded, but to the extent that liabilities exceed assets, these unfunded liabilities should be shown on the sponsor's balance sheet (De Vries, 2010).

Similarly, greater attention is being placed on the impact of social security liabilities and assets on the government's balance sheet. There is a global ongoing debate to increase the transparency of the liabilities (obligations) ${ }^{3}$ of SSSs. The disclosure of the abovementioned liabilities has been frequently requested by national and international reporting bodies for financial reporting.

Statistical, accounting and actuarial guidelines for valuing the liabilities of social security (SS) programmes are published by the United Nations (EC et al. (2009), EU (Eurostat, 2010), International Monetary Fund (IMF, 2014), International Public Sector Accounting Board (IPSASB, 2017 a, 2017 b, 2017 c; 2019), International Actuarial Association (IAA,

\footnotetext{
${ }^{1}$ The definitions of "mandatory spending” and other terms appear in the Glossary, appendix 1 . The benefits paid by social security systems are considered mandatory spending.

${ }^{2}$ In some countries, this is also due to a bad practice known as "populism in pensions" (see Appendix 1).

${ }^{3}$ In this paper the terms liability and obligation are understood to be synonyms given that in actuarial language we usually speak about assets and liabilities, but some authors distinguish both terms. For IAA (2018), an obligation is a promise based on current law or regulations, or on a social contract; a commitment to pay a particular sum of money; a duty or a responsibility. An obligation is also a liability when there is a legal responsibility for the obligation, as in a legal debt.
} 
2013; 2018) and national standard setters such as the Accounting Standards Board (ASB) of the American Academy of Actuaries (AAA, 1998) and the Canadian Institute of Actuaries (CIA, 2017), to name just a few. These standard setters have different approaches to the accounting, actuarial, funding and disclosure requirements of different types of pension programmes; and are ambiguous, inconsistent, and are not fully enforced. Even when standards reach the same conclusion, the rationale is different (Wiener and Stokoe, 2018).

This paper is in line with the ongoing debate on how to recognize and measure assets and liabilities of SSSs. It develops a full accounting model for monitoring the solvency of a notional defined contribution (NDC) pension scheme (see Appendix 1) with permanent disability and minimum pension benefits.

The paper builds on previous work carried out dealing with the so-called "Swedish" open group (SOG) approach, and with pension schemes combining permanent disability and retirement within an NDC framework. The starting points are the papers by VenturaMarco and Vidal-Meliá (2014), Pérez-Salamero et al. (2017), TSPS (2018) and VidalMeliá et al. (2018). Ventura-Marco and Vidal-Meliá (2014) inspired by the Swedish model, developed as a theoretical basis for compiling a Swedish ABS for a DB PAYG scheme with retirement and disability benefits. Pérez-Salamero et al. (2017) develop a Swedish-type ABS for an NDC scheme with disability and minimum pension benefits. TSPS (2018) is the most recent annual report of the Swedish pension system and presents its financial status and income statement along with a description of the accounting principles used for valuing the system's assets and liabilities. Finally, the paper by VidalMeliá et al. (2018) develop a social insurance accounting model for an NDC scheme combining retirement and long-term care (LTC) contingencies.

The paper uses the Swedish pension system's most recent annual report as a benchmark (TSPS, 2018), and extends the model developed by Pérez-Salamero et al. (2017) by adding an income statement, which fully explains the reasons behind the changes in the system's solvency by type of benefit. In line with the reference model, assets and liabilities are measured at present value at each reporting date, and changes in present value are reported in each period as income or expenses and are included on the income statement.

This paper contributes to filling a gap in the literature because little attention has been paid to the SOG approach. It is at least surprising that in a recent special issue of an international journal ${ }^{4}$ which addressed the topic of the actuarial and financial reporting of SS obligations, none of the published papers referred to this approach. We are convinced that our paper is timely because there are important issues that need further research, for instance, the link between the SOG approach and the most classical approaches explored, and also because our proposed income statement could serve as a guidance to improve the true and fair view (see Appendix 1) of the Swedish actuarial balance sheet through a better determination of the changes in the system's net worth.

The structure of the paper is as follows. After this introduction, Section 2 looks into the methodology labelled as "Swedish" open group developed for measuring liabilities and assets in contributory SSSs; the most relevant features are identified and compared to the traditional approaches and a literature review is also provided. Section 3 presents the main characteristics of a social insurance accounting model for an NDC scheme including retirement, disability and minimum pension benefits (MPB) for both contingencies.

\footnotetext{
${ }^{4}$ International Social Security Review, Vol 71, issue 3.
} 
Special attention is paid to the income statement, the real novelty of the model and the rationale behind why presenting the income statement of a hypothetical alreadyfunctioning NDC (PAYG) scheme is important. Section 4 provides a numerical example, which illustrates annual changes in the system's financial position by means of an income statement for an already-functioning system. The paper ends with the concluding comments, and three appendices. The first of these is a glossary. The second one gives a brief picture on how disability benefits are treated within the NDC framework and its relation with minimum pension benefits, while the third one provides the technicalities of the model, which makes it possible to integrate disability and minimum pension benefits within the NDC framework.

\section{2.-MEASURING ASSETS AND LIABILITIES IN SOCIAL SECURITY SCHEMES: MAIN APPROACHES AND LITERATURE REVIEW.}

Social security pension schemes (SSSs, see Appendix 1)) are considered as contributory schemes because they are mainly financed by employer and employee contributions and /or earmarked taxes. The main social benefit payable in cash is the pension provision for retirees. However, others may be entitled to pensions, for example widows and the permanently disabled (see Appendix 1).

Generally speaking, the payment of a specified number, or amount, of contributions creates a valid expectation that an individual or household will receive benefits based on those contributions made. These expectations may be strengthened by communications regarding personal details of estimated future benefits such as the "Social Security Statement” in USA (Armour, 2018) or the “Orange Envelop” in Sweden (Sundén, 2012) to name just a couple of examples ${ }^{5}$.

As far as measuring the liabilities and assets for SSSs is concerned, there are four approaches, three of them are reasonably well-known; but another one is relatively unknown even for most pension experts. Table 1 summarizes the main features of the approaches analyzed below.

\section{1.-Closed group without future accruals (CG).}

Under this approach, the plan's liabilities are equal to the present value of all expected future benefits to pensioners and all accrued rights of current affiliates. Accrued pension rights are due to already paid social contributions by current workers and remaining pension entitlements of existing pensioners.

Assets include the amount of the buffer fund of the SSS if it were the case. Some schemes accumulate assets as a reserve in case liquidity or other adversities occur or to stabilize future contribution rates due to population ageing.

The liability determined under this approach is called the accrued-to-date pension liability (ADL), and it can be interpreted as the amount of resources that has to be set aside today in order to finance all the pension rights that have been earned up to a given year (see Appendix 1). Although the pension system is assumed to be closed and given that pensions in payment are estimated in present value terms, from the actuarial perspective, it is necessary to take into account the number of years elapsed between the highest age to which it is possible to survive and the youngest cohort of pensioners.

\footnotetext{
5 The paper by Regúlez-Castillo and Vidal-Meliá (2012) provides a brief summary of information on Sweden, Chile, Germany, the United Kingdom, Finland, the United States, France, Japan and Canada concerning the most important elements included in the annual individual statement sent to contributors.
} 


\begin{tabular}{|c|c|c|c|c|c|}
\hline \multirow{2}{*}{ Approach } & \multicolumn{2}{|c|}{ Time horizon (valuation period) } & \multirow{2}{*}{$\begin{array}{l}\text { Number of new } \\
\text { cohorts of } \\
\text { contributors } \\
\text { included }\end{array}$} & \multirow{2}{*}{$\begin{array}{l}\text { Projections } \\
\text { (explicit) }\end{array}$} & \multirow{2}{*}{$\begin{array}{c}\text { Suitable for... } \\
\text { Applied to... }\end{array}$} \\
\hline & System & Actuarial perspective & & & \\
\hline $\begin{array}{l}\text { Closed group } \\
\text { without future } \\
\text { accruals (CG) }\end{array}$ & $\begin{array}{l}\text { Zero, the system is assumed } \\
\text { to be closed. }\end{array}$ & $\begin{array}{l}\text { Pensions in payment are } \\
\text { estimated in present value } \\
\text { terms. Years elapsed between } \\
\text { the highest age to which it is } \\
\text { possible to survive and the } \\
\text { youngest cohort of pensioners. }\end{array}$ & Zero. & No & $\begin{array}{c}\text { Fully-funded DC } \\
\text { schemes or PAYG } \\
\text { schemes when the } \\
\text { decision is made to } \\
\text { cease it } \\
\text { immediately. } \\
\text { (Eurostat, 2011). }\end{array}$ \\
\hline $\begin{array}{l}\text { Closed group } \\
\text { with future } \\
\text { accruals } \\
\text { (CGFA) }\end{array}$ & $\begin{array}{l}\text { Years elapsed between the } \\
\text { retirement age and the } \\
\text { youngest cohort of } \\
\text { contributors. }\end{array}$ & $\begin{array}{l}\text { Future and current pensions in } \\
\text { payment are estimated in } \\
\text { present value terms. Years } \\
\text { elapsed between the highest } \\
\text { age to which it is possible to } \\
\text { survive and the youngest } \\
\text { cohort of contributors. }\end{array}$ & $\begin{array}{l}\text { Zero, the system is } \\
\text { considered as if it } \\
\text { were in operation } \\
\text { until the last } \\
\text { contributor dies. }\end{array}$ & No & $\begin{array}{l}\text { Fully-funded DB } \\
\text { schemes or PAYG } \\
\text { schemes when no } \\
\text { new entrants are } \\
\text { allowed. }\end{array}$ \\
\hline $\begin{array}{l}\text { Hybrid Open } \\
\text { group (HOG) }\end{array}$ & $\begin{array}{l}\text { An arbitrary time period } \\
\text { corresponding to the allowed } \\
\text { number of new cohorts of } \\
\text { contributors (from } 50 \text { to } 75 \\
\text { years). }\end{array}$ & $\begin{array}{l}\text { Years elapsed between the } \\
\text { highest age to which it is } \\
\text { possible to survive and the } \\
\text { youngest cohort of contributors } \\
\text { plus the arbitrary time period. }\end{array}$ & $\begin{array}{c}\text { An arbitrary number } \\
\text { (from } 50 \text { to } 75 \text { ). The } \\
\text { system is considered } \\
\text { as if it were } \\
\text { functioning until the } \\
\text { last contributor of the } \\
\text { last cohort of entrants } \\
\text { assumed as a } \\
\text { contributor dies. }\end{array}$ & $\begin{array}{l}\text { Yes, it is necessary } \\
\text { to make explicit } \\
\text { projections of } \\
\text { economic, financial } \\
\text { and demographic } \\
\text { variables }\end{array}$ & $\begin{array}{l}\text { PAYG schemes } \\
\text { when only a limited } \\
\text { number of new } \\
\text { cohorts of entrants } \\
\text { are allowed. }\end{array}$ \\
\hline
\end{tabular}




\begin{tabular}{|c|c|c|c|c|c|}
\hline \multirow{2}{*}{ Approach } & \multicolumn{2}{|c|}{ Time horizon (valuation period) } & \multirow{2}{*}{$\begin{array}{l}\text { Number of new } \\
\text { cohorts of } \\
\text { contributors } \\
\text { included }\end{array}$} & \multirow{2}{*}{$\begin{array}{l}\text { Projections } \\
\text { (explicit) }\end{array}$} & \multirow{2}{*}{$\begin{array}{l}\text { Suitable for } \\
\text { Applied to... }\end{array}$} \\
\hline & System & Actuarial perspective & & & \\
\hline $\begin{array}{l}\text { Open group } \\
\text { (PG) }\end{array}$ & $\begin{array}{l}\text { An arbitrary time period from } \\
75-95 \text { years to infinite }\end{array}$ & $\begin{array}{l}\text { Under a cash flow approach } \\
\text { coincides with the system time } \\
\text { horizon }\end{array}$ & $\begin{array}{c}\text { An arbitrary number } \\
\text { from 75-95 years to } \\
\text { infinite. It is assumed } \\
\text { an ongoing basis for } \\
\text { the scheme. }\end{array}$ & $\begin{array}{l}\text { Yes, it is necessary } \\
\text { to make explicit } \\
\text { projections of } \\
\text { economic, financial } \\
\text { or demographic } \\
\text { variables }\end{array}$ & $\begin{array}{l}\text { PAYG and Partially } \\
\text { funded schemes. } \\
\text { (EC, 2018); (BOT, } \\
\text { 2018); (AAD, } \\
\text { 2017); (OSFIC, } \\
\text { 2018) }\end{array}$ \\
\hline $\begin{array}{l}\text { “Swedish” open } \\
\text { group (SOG) }\end{array}$ & $\begin{array}{l}\text { Valuation formulas consider } \\
\text { only pensioners and } \\
\text { contributors at the valuation } \\
\text { date, but... }\end{array}$ & $\begin{array}{l}\text { The use of the expected time } \\
\text { between payment of } \\
\text { contributions and receipt of } \\
\text { pensions (turnover duration, } \\
\text { TD), and other assumptions, } \\
\text { makes this approach equivalent } \\
\text { to a perpetual time horizon. }\end{array}$ & $\begin{array}{l}\text { Equivalent to an } \\
\text { infinite number of } \\
\text { cohorts. }\end{array}$ & $\begin{array}{l}\text { There is no need for } \\
\text { explicit projections. } \\
\text { It is assumed that } \\
\text { the system's rules } \\
\text { and the economic } \\
\text { and demographic } \\
\text { conditions } \\
\text { prevailing at the } \\
\text { time of the valuation } \\
\text { remain constant. }\end{array}$ & $\begin{array}{l}\text { PAYG schemes, } \\
\text { especially for } \\
\text { NDCs. (TSPS, } \\
\text { 2018) }\end{array}$ \\
\hline \multicolumn{6}{|c|}{ Source: Own } \\
\hline
\end{tabular}


Starting in 2017, EU regulations require all Member States to disclose ADL using a standard actuarial cost method and common assumptions, both for SSSs and for unfunded defined benefit (DB) schemes (see Appendix 1) covering civil servants (Eurostat, 2010).

These pension liabilities are not required to be included in the government's core national accounts, but they have to be disclosed in a supplementary table, referred to as Table 29.

This methodology may provide relevant information for pension systems financed using a full advance funding financing method (see Appendix 1), but the CG approach does not allow for the assessment of the financial sustainability (see Appendix 1) of SSSs, which are typically financed on a pay-as-you-go/partially funded basis (see Appendix 1).

Large pension entitlements do not necessarily mean unsustainable pension schemes, and similarly, small pension entitlements do not mean that the respective pension schemes are fiscally stable in the long term (Eurostat, 2011). As Stavrakis (2018) states, if the ADL figures, which by nature are of a very large size, are disclosed alone without sufficient and proper explanation, or without complementary information, they could be easily misused or misinterpreted by the media and other external users, creating an unwarranted negative public opinion or perception of the SSSs.

Wiener and Stokoe (2018) conclude that the use of the ADL is problematic. It is not only potentially misleading but may encourage "accounting arbitrage", where countries are incentivised to structure systems in certain ways to reduce the value placed on pension liabilities. In short, it can be said that ADLs capture (in an unsuitable way) only one side of a pension scheme's balance sheet which is considered from a Social Security Administration's point of view, the most valuable instrument for reporting the system's financial status (Vidal-Meliá et al., 2018).

\section{2.-Closed group with future accruals (CGFA).}

The system's liabilities are equal to the present value of all expected future benefits to beneficiaries and all accrued and future rights of current contributors (affiliates). Assets include the amount of the existing reserve from the pension system (i.e., any investable assets) and the present value of future contributions with respect to future benefits of current affiliates.

To a large extent, this approach is in line with IPSASB, 2019. According to this accounting standard for the public sector, an entity shall recognize a liability for a social benefit scheme when the entity has a present obligation for an outflow of resources that results from a past event. Similarly, IPSASB, 2017b, indicates that assets are resources controlled by an entity as a result of a past event. This definition is consistent with those used by other accounting standard setters, such as the International Accounting Standards Board (IASB). Given that a past event is required before assets and liabilities are recognized, as will be seen later in this paper, the open group approach is ruled out in measuring the assets and liabilities (Mason, 2018).

The definition of the CGFA corresponds to the situation where the SSS continues its existence until the last contributor dies, while no new entrants are allowed; both the future contribution of existing members and their new rights are therefore allowed under current rules. Since future and current pensions in payment are estimated in present value terms, from an actuarial point of view, the real valuation period comprises the number of years elapsed between the highest age to which it is possible to survive and the youngest generation of contributors. 
CG approaches are suitable for fully-funded schemes, however its application to PAYG schemes always produce under-funding and are not reflective of prospective funding for plans relying on future contribution financing on an ongoing basis (Drouin et al., 2018).

Some international organizations and several authors (ISSA-ILO, 2016; IAA, 2013 and 2018, D'Ambrogi-Ola and Brown, 2018) have criticized the use of CG approaches when they are not consistent with the financing method adopted by the SSS. They recommend to the SS institution to disclose, in a supplementary note, alternative calculations in coherence with its financing approach.

\section{3.-Open group (OG).}

The system's liabilities include the present value of all current beneficiaries and contributors to the SSS and the contributions and benefits of new affiliates under current rules; the range of options extends from including only children not yet in the labor force, to an infinite perspective. Usually, an arbitrary time period is chosen (75-95 years) and the methodology is applied over that period.

This approach can be used to determine whether a SSS's buffer fund (if any) in combination with future contributions (which together comprise the system's assets) is expected to be sufficient to pay for all future benefit expenditures (the system's liabilities).

This approach is widely used by SS administrations and other related public institutions. The actuarial balance approach (US AB) ${ }^{7}$ used in the United States for its Old-Age, Survivor and Federal Disability Insurance Trust Funds (BOT, 2018), the Japanese "finite period of financial equilibrium" method (JAM) applied for the National Pension and Employees' Pension Insurance (AAD, 2017), the Canadian actuarial valuation report (CAVR) on the Canadian Pension Plan (CPP), (OSFIC, 2018), and the Ageing Working Group of the Economy Policy Committee (the "AWG”) pension reporting (EC, 2018) are undertaken based on this OG approach.

Partially funded systems, as well as pay-as-you-go ones, represent social contracts where, in any given year, current contributors allow the use of their contributions to pay current beneficiaries' benefits. As a result, such social contracts create claims for current and past contributors to the contributions of future contributors. The proper assessment of the financial sustainability of a PAYG or partially funded system by means of its balance sheet should take into account these claims. (AAA, 1998; OSFIC, 2018; Drouin et al., 2018).

The ABS can be produced using open-group projections. The projections may be based on either a cash-flow approach or a cohort-based approach (Drouin et al., 2018).

Under a cash-flow approach, future in-flows and out-flows of the system are projected over a long period (at least 75 years), independently of the cohorts of contributors to which they relate. It means that in the last year of the projection period, the latest cohorts of affiliates included in the projection will have paid contributions for some time but the benefits to which they will eventually be entitled are not entirely paid. It also means that there exists a remaining liability at the end of the projection period (pension rights accumulated on the last day of the projection period that are not yet paid) that is not part of the ABS.

\footnotetext{
${ }^{7}$ See Appendix 1 for a brief definition of the several actuarial reports (US, Canada, Japan and pension reporting).
} 
Under a cohort-based approach (labeled as Hybrid Open group (HOG) in Table 1), the ABS includes all cash flows related to a certain number of cohorts (e.g. contributors and beneficiaries at the valuation date plus, for example, 75 cohorts of future contributors). It means that the cash flows must be projected until the time the last benefit payment of the last beneficiary of these 75 cohorts of future contributors is made, consequently, from an actuarial point of view, the real valuation period comprises the number of years elapsed between the highest age to which it is possible to survive and the youngest cohort of contributors plus the arbitrary time period. This approach can be used to assess the financial sustainability of PAYG schemes when only a limited number of new cohort entrants are allowed.

Finally, several international associations such as the International Federation of Accountants (IPSASB, 2017a, b and c), the International Actuarial Association (IAA, 2013 and 2018) and the International Social Security Association (ISSA and ILO, 2016) also recognize that the assessment of the long-term sustainability of SSSs should take into account future benefits as well as future revenue.

\section{4.-The "Swedish" open group (SOG).}

Another methodology to be taken into account to measure the assets and liabilities for a SSS is the one used by the Swedish authorities since 2001 (TSPS, 2002). In Sweden there is a notional defined contribution (NDC) pension scheme in force, a special type of PAYG pension system ${ }^{8}$.

SOG is based on the CG method that has been modified to make it equivalent to OG. It can be considered "open group" at any particular year t because to value the system's assets and liabilities, it takes new entrants into account and assumes that there will be contributions to meet liabilities, but valuation formulas consider only pensioners and contributors at the valuation date ${ }^{9}$.

A central accounting principle of this approach is that the system's assets and liabilities are valued on the basis of events and transactions that are verifiable at the time of valuation, with no need for explicit projections. It is assumed that the system's rules and the economic and demographic conditions prevailing at the time of the valuation remain constant.

As we will see later, the value of the contribution flow (the contribution asset) is estimated by multiplying the current contribution revenue of the system by the expected time between payment of contributions and receipt of pensions (turnover duration, $T D$ ), and this could be interpreted as equivalent to discounting an assumed perpetual constant flow of contributions by the inverse of the $T D$. This involves an OG approach with a perpetual time horizon.

This way of measuring the system's assets and liabilities has a high degree of transparency and needs no complicated projections of economic, financial or demographic variables, which could easily have a biased effect on the sustainability and solvency indicators. This approach is suitable to introduce automatic balance mechanisms

\footnotetext{
${ }^{8}$ The papers by Qi et al., (2018) and Palmer and Könberg (2019), to name just a couple, as well as TSPS (2018), are good sources for the interested reader in the real aspects of the NDC Swedish pension system: the financial stability, factors influencing the adequacy of benefits, and its interplay with other components of the pension system or its effect on prolonging the working life of the affiliates.

${ }^{9}$ PAYG systems bear a fundamental risk related to the demographic variable "new entrants" and to their future contribution capacity (Melis and Trudda, 2012). This issue clearly goes beyond the limits of our study.
} 
(ABMs, see Appendix 1), given that the possibly endless debates as to the accuracy of long term projections are avoided.

\subsection{1.-Literature review on the use of the ABS to assess the solvency of SSSs.}

Based on the SOG approach, several papers have explored the use of actuarial balance sheets (ABS) to assess the solvency of SSSs. The ABS can be defined as a financial statement listing the pension system's obligations to contributors and pensioners at a particular date, with the amounts of the various assets (financial and mainly through contributions) that underwrite those commitments. As Boado-Penas et al. (2008) have pointed out, the main aim of the ABS is to give a true and fair view (TFV) ${ }^{10}$ of the pension system's assets and liabilities at the beginning and end of the fiscal year and, by comparing these figures, to determine the change in net worth. It can be said that the pension system is solvent at the valuation date when the relation between the assets and liabilities of the system is equal to or greater than 1.

From a theoretical perspective, Settergren and Mikula (2005) develop the main principles for reporting the financial position of retirement NDC schemes within a balance sheet. Boado-Penas et al. (2008) develop the main entries to compile the actuarial balance sheet for a DB PAYG scheme. Vidal-Melia and Boado-Penas (2013) obtain the analytical properties of the contribution asset and endorsed its soundness as a measure of the assets of a PAYG scheme. Ventura-Marco and Vidal-Meliá (2014) develop the theoretical basis for drawing up a "Swedish" type ABS for a DB PAYG scheme with retirement and disability benefits while Pérez-Salamero et al. (2017) propose a "Swedish" ABS for an NDC scheme with disability and minimum pension benefits. Vidal-Meliá et al. (2018) present a social insurance accounting model for an NDC scheme combining retirement and long-term care (LTC) contingencies. The model also includes an income statement to determine any change in the system's net worth.

From an applied perspective, the annual reports of the Swedish pension system are the main references. However, some researchers based on the (actuarial) balance sheet approach have presented applications to several countries such as Japan, New Zealand, Finland, Spain, Canada, Switzerland, Germany and Belgium.

Takayama (2005) explains the 2004 pension reforms in Japan using the balance sheet approach to analyse the implications for the Japanese economy. Rashbrooke (2008) explores the application of actuarial accounting methodology developed by the Swedish authorities to the New Zealand flat rate social security pension. Lassila and Valkonen (2008) apply the Swedish balance mechanism, based on the ratio of assets to liabilities emerging from the balance sheet, to the Finnish private-sector earnings-related pension system and simulate the future with stochastic population projections and asset yields.

Boado-Penas et al. (2008) provide the first estimate of the actuarial balance of the Spanish contributory pension system for the old-age contingency, based on official data, whereas Vidal-Meliá et al. (2009), aimed at showing the usefulness of automatic balance mechanisms, present a comparison between the official balance sheet for the Swedish notional account system and the balance sheet for the Spanish contributory pension system. Finally, Vidal-Meliá (2014) compiles two actuarial balance models for the Spanish public retirement pension system at 1-1-2010 and 31-12-2010 and then compare them with those for Sweden and the USA.

\footnotetext{
${ }^{10}$ In the Swedish pension system, the financial report (ABS) is audited in accordance with the Regulations on Annual Reporting of the Financial Position and Development of the Earnings Related to the Old Age Pension System (2002:135) (TSPS, 2018).
} 
For Canada, with the aim of making a comparison with the official actuarial valuation report of the CPP, Billig and Ménard (2013) make a practical adaptation of the methodology used to compile the Swedish ABS. Metzger (2018) uses the Swedish ABS methodology to assess the fiscal sustainability of the Swiss old-age pension system (AHV). For the German statutory pension insurance, Metzger (2019) estimates a balance sheet for the years 2005 to 2014 considering old-age, disability and survivors' pension entitlements. Finally, Alonso-García and Devolder (2019) apply a continuous overlapping generations (OLG) model to assess the solvency of a generic NDC scheme for the population of Belgium. Solvency in their setting represents a longitudinal perspective as it compares the liabilities towards all participants of the scheme (contributors and retirees) with a contribution asset, that is, the actuarial balance sheet as developed in Settergren and Mikula (2005).

It is worth mentioning that some of the papers quoted presenting applications for the above-mentioned countries do not develop the theoretical basis for making the application, especially those including disability and survivors' pension entitlements and non-contributory benefits. Indeed, some authors warn us that the exercise of compiling the balance sheet should be viewed simply as an illustration.

\section{3.-THE ACCOUNTING MODEL}

This section presents the main characteristics of a social insurance accounting model for an NDC scheme including retirement, disability and minimum pension benefits (MPB) for both contingencies. Special attention is paid to the income statement and the specificities for a (fictional) already-functioning NDC scheme. This section also offers reasons why presenting the income statement of an already-functioning NDC (PAYG) scheme is important.

It seems difficult to hide the real importance of including a disability benefit in an NDC scheme. Disability Insurance should be an integral part of SSSs; given that it is much more than just a retirement program. This benefit protects afiliates in case they can no longer support themselves due to a severe and long-term disability.

It is worth highlighting that in most developed countries a dramatic increase in the disability beneficiaries has been observed (Autor and Duggan, 2006; OECD, 2019). There are a variety of reasons explaining this fact: population changes and ageing trends (CRS, 2018); economic factors, including labour market fluctuations and the availability and attractiveness of work (Benítez-Silva et al., 2010); lower transaction costs on disability applications (Foote et al., 2019), movement from or to other social welfare schemes (Lindner, 2016; Borghans, et al., 2014); changes to the prevalence of disability, or different types of disability, within the population; increasing the normal retirement age (Li, 2018), changes to the standard medical definition and diagnosis practices (GarcíaGómez and Gielen, 2018); and changes to qualification criteria including means testing (Low and Pistaferri, 2015; Golosov and Tsyvinski, 2016) and medical assessment. Changes in education levels also play an important role in future trends in Social security disability (Michaud et al., 2018), and the long term effects of education on economic outcomes, such as the receipt of Social Security Disability Insurance (DI) and the early claiming of Social Security retirement benefits (Venti and Wise, 2005)

In short, the issue of disability insurance has multiple implications for society, which go beyond the objective of this paper, but it is not an exaggeration to say that disability costs need to be closely monitored, and our paper covers this existing gap in the NDCs literature. 
The study of how disability benefits are treated within the NDC framework and its relation with minimum pension benefits (Appendix 2), shows there are several issues to be improved: discontinuities in benefit levels occurred when disability benefits are converted into retirement benefits at the ordinary retirement age (Sweden), disability pensions are converted into old age pensions according to NDC rules, but the old-age pension cannot be lower than the granted disability benefit (Latvia); in Norway, disability pensioners are partially exempted from life age adjustments, so the "system" gives incentives to become disabled before obtaining the retirement pension. In Italy the formula used to calculate the disability pension does not provide a clear link between benefits and contributions and also includes the possibility of paying survivor benefits. Generally speaking, in the countries analysed, a lack of transparency can be observed in the redistribution embedded in the defined benefit formula used to calculate disability benefits. The specific life expectancy of the disabled people by age is not used either to compute the disability benefit, which is surprising from an actuarial point of view. Giving that the NDC pension operates on a PAYG basis but mimicking a FDC scheme, the idea of using the specific mortality for disabled people comes naturally to actuarial thinking as a way of improving the link between benefits and contributions.

The paper by Pérez-Salamero et al. (2017) designed a Swedish type ABS for an NDC scheme with disability and minimum pension benefits. The way disability is treated in their proposal has several advantages to overcome some of the above mentioned drawbacks. Briefly, it makes it easier to integrate both contingencies into a coherent NDC framework, the formula for calculating the disability benefits is embedded into the general formula for determining the retirement benefits, and the integrated system is financially sound and sustainable over time. Furthermore, it introduces redistribution in a very transparent manner and it allows the sponsor (the state) to take into account trends in disability, longevity and other sources of risk in "pricing” benefits more effectively.

The above mentioned paper on the pure NDC model shows that in a steady and well balanced (unrealistic) state the system's total liabilities match perfectly with the system's total contribution asset. The two integrated contingencies (retirement and disability) are in financial equilibrium. They also included a numerical example that shed light on the real applicability of their proposal and the impact of introducing the MPB on the ABS. However, they did not describe the more realistic case for an already-functioning NDC scheme nor did they develop the income statement which fully explains the reasons behind the changes in the system's solvency by type of benefit. The technical details of the proposed model are not developed either.

The income statement gives a full explanation of the reasons for changes in the system's solvency, in our model the reasons are also detailed by type of benefit. In this type of pension scheme, changes in net worth are affected by economic and demographic factors, and financial markets if the system has a reserve fund. Usually, the main factor in the short term would be growth in employment and contribution basis, whereas in the long term, demographic factors would be by far more important. 


\section{1.-The "Swedish" actuarial balance sheet for a (fictional) already-functioning NDC scheme combining retirement and disability contingencies with a MPB.}

Very briefly, the main features of the proposed scheme are the following:

There are two types of pensioners: retirement pensioners and disability pensioners. The affiliates are the active workers, who contribute to both retirement and disability contingencies. The disability is linked to working ages. There is a defined contribution rate (fixed over time), $\theta_{a}$, to cover both contingencies.

Pension contributions are tracked in accounts which earn interest on accumulated contributions equal to the change in the covered wage bill growth ${ }^{11}$ plus the so-called "survivor dividend". These inheritance gains are made up of the account balances of participants (not disabled) who do not survive until retirement and which are distributed to the accounts of the surviving contributors on a birth cohort basis (Boado-Penas and Vidal-Meliá, 2014; Arnold-Gaille et al., 2016; Vidal-Meliá et al., 2016; Knell, 2018).

The amount accredited in the notional account is an accumulation of the contributions made by the deceased, the corresponding survivor dividends that were distributed and the returns generated over the participant's working life.

The age giving entitlement to retirement pension, $x_{e}+A$, is fixed (in the theoretical model), so early retirement is not considered. In the numerical example this assumption is relaxed, there is an age interval to getting retirement.

We also assume that participants' lives last $\omega-x_{e}$ periods, where $\omega$ is the maximum lifespan and $x_{e}$ is the earliest age of entry into the system.

It is assumed that the ages for eligibility to receive disability benefits are to be found in the age interval $\left[x_{e}+1, \omega\right]$, and workers acquire insured status from the first day of employment, with no prior contribution requirement or waiting period. We assume that disability is an absorbing state and that once disabled, an individual remains disabled for the rest of his/her life. It is considered that the only reason for a disabled worker's benefit to terminate is through the death of the pensioner. Conversions or recoveries are not taken into account.

In short, the initial amount of the benefit depends on several elements, the most important being the pension balance accumulated at retirement or at the time of disability and the minimum pension benefit. However, there are other elements that also matter: the expected mortality of the cohort in the year the contributor reaches retirement, the disability incidence rates by age, the expected mortality of disabled persons, and a notional imputed future indexation rate, $\alpha$ (see Technical Appendix).

In practice, the supplement to the MPB would be paid only if the beneficiary has assets below a specific maximum, i.e. the system demands an asset test (see Appendix 1).

With the described rules of the pension system, an ABS for a hypothetical alreadyfunctioning NDC scheme combining retirement and disability contingencies with a MPB can be compiled as shown in Table 2.

As depicted in Table 2, the two contingencies are disclosed and the commitments deriving from non-contributory rights (NCRs) are accounted for. This ABS splits the system into two parts: the actuarial part (pure NDC) and the redistributive part, which includes the

\footnotetext{
${ }^{11}$ Another notional rate could be used: the income growth per capita, the GDP growth, the overall contribution revenue growth, etc.
} 
assets and liabilities originating from NCRs, but for the sake of brevity the ABS is shown as a whole.

The right-hand side of Table 2 shows the liabilities and the sponsor support (capital) of the ABS.

The liabilities to pensioners for retirement, Pen_(R), and disability, Pen_(D), can be defined as the present value of the amount of all the benefits in payment stemming from contributory rights at the valuation date of the balance sheet. The interest rate for discounting liabilities to pensioners is taken to be the growth rate of the covered wage bill $(G)$.

\begin{tabular}{|c|c|}
\hline Table 2: The ABS for an already-functioning NDC scheme combining retirement and \\
disability contingencies with a MPB.
\end{tabular}

As far as the liabilities to pensioners for disability are concerned, and contrary to the Swedish model, we do not apply "pension reclassification”. If we were to consider those disabled people who reach retirement age as retirement pensioners, the apparent liability to pensioners for retirement (disability) would increase (decrease) noticeably.

Given that the system provides a minimum pension benefit for both contingencies, this side also shows the liability to pensioners for retirement, Pen_(R)_NCR, and disability, Pen_(D) _NCR, caused by NCRs. The liability is calculated the same way as in the actuarial part. It is worth remenbering that if the amount of the initial pension (retirement or disability) is below a minimum value, the amount is supplemented up to the minimum pension benefit. 
The liabilities to contributors for retirement, Con_(R), and disability, Con_(D), are equivalent to the notional capital accumulated in the participants' accounts (formed by the contributions made by participants, plus the return deriving from the notional rate of interest credited to those accounts plus the survivor dividend).

Depending on the criteria chosen to quantify the NCRs of the contributors (Vidal-Meliá et al., 2018), there could be two aditional items presented on the balance sheet, liabilitiy to contributors for retirement, Con_(R)_NCR, and disability, Con_(D)_NCR, due to NCRs.

If the "Swedish" principle was applied, whereby the liabilities of the pension system are valued mainly on the basis of events and transactions that are verifiable at the time of valuation with no need for explicit projections, the liability to contributors for retirement and disability due to the NCRs should be zero; i.e. Con_(R)_NCR = Con_(D)_NCR = 0. Instead, if it were to make explicit projections, by taking into account the future wage development, the inclusion of a MPB would imply the valuation of the accrued minimum benefit by means of the prospective measure by the forecasted method. As a result, these liabilities, caused by NCRs, could have a positive value at the valuation date.

Financial liabilities, FD, are liabilities on the actuarial balance sheet resulting from a (temporary) accumulation of treasury deficits. In some countries, for instance in the USA, the pension system is not allowed to borrow under any circumstance, whereas in others, Spain is one of them, the system increases its financial debt to pay for the scheduled benefits.

Sponsor support or Capital, SS, this item is the counterpart of the buffer fund corresponding to the sponsor (the state in a public plan); this allows for possible annual shortfalls in the system's income to be dealt with by selling financial assets. In reality, this is a security mechanism; the sponsor offers a certain protection against the financial instability due to possible annual shortfalls in the system's income.

The entries shown on the right-hand side of Table 2 also include the accumulated surplus, As_(R+D), and the actuarial profits for the (annual) period, $\mathbf{P} \_(\mathbf{R}+\mathbf{D})$. The accumulated surplus is the pension system's “accumulated gain” or net worth, which is owned by the system's sponsor, in this case the state. The annual gain is the difference between the change in the value of the assets and the actuarial liabilities; the difference should be positive. Both entries could be reported by contingency.

The left-hand side (or assets side) of Table 2 lists the main entries that can appear in the ABS.

The contribution asset for retirement, CA_(R), and for Disability, CA_(D). As stated in the previous section, in PAYG systems, the contribution flow is considered as the principal asset. The Swedish concept of the value of the (future) contribution flow is expressed as the contribution asset: the maximum level of liabilities that would have existed on the last day of the accounting period if the age-related income distribution, age-related mortality and disability, the size of the contribution (tax) base, the structure of pensiones and the pension system rules were never changed (Boado-Penas and VidalMeliá, 2013). Once the process for obtaining the system's turnover duration has been developed (see the technical appendix), the contribution asset is simple to calculate: it is the product of the size of the flow per time unit, which in practice is a year, and the expected time between payment of contributions and receipt of pensions, the so called turnover duration (TD). 
In this model, the $T D$ for the system could be interpreted as the number of years expected to elapse before the committed liabilities to contributors and pensioners for retirement and disability are completely renewed at the current contribution level. Each monetary unit enters the system as if it were paid by a contributor of $A_{C}$ years and remains within the contribution liability until retirement age is reached (pay-in). It is then received by a pensioner aged $A_{r}$ years (pay-out). (See details in Technical Appendix)

This side could include a buffer fund or reserve fund. This entry is the value of the stock of financial assets owned by the system, FA. The funds' purpose is to compensate for temporary deficits in pension contributions in relation to pension disbursements. This asset could result from an accumulation of treasury surpluses or simply for the sake of liquidity resulting from an extraordinary contribution made by the sponsor: Ss

Since the system provides MPBs, its solvency and transparency needs to be preserved by including an asset counterpart to underwrite the liabilities caused by NCRs. To do this, and depending on the approach adopted (Pérez-Salamero et al., 2017; Vidal-Meliá et al., 2018) two additional entries can appear: a special type of public contribution asset: PCA_(D) and PCA_(R), or a buffer fund: BF_(D) and BF_(R), financed from general government revenues. It is important to note that disability benefits, survivor benefits and guaranteed minimum pensions are excluded from Swedish accounting because they are not part of the NDC system but are financed separately, basically using general tax revenue (TSPS, 2018).

We can also find on this side the accumulated deficit, Ad_(R+D), and the actuarial losses for the period, $\mathbf{L} \_(\mathbf{R}+\mathbf{D})$. The accumulation of actuarial losses in each period determines the value of the accumulated shortfall at the date of the balance sheet, and the "losses in each period" represents the difference between the variations of the value of the liabilities and assets for the period, the opposed concept of accumulated surplus. The actuarial loss is equivalent to the increase in the accumulated Deficit or the reduction in the accumulated Surplus, depending on the situation.

Finally, the net worth is a balancing item that stems from valuing assets and liabilities (including Sponsor support) according to the accounting principles used on the balance sheet date. Net worth can be positive, negative, or zero, and it is equal, to the accumulated surplus plus the profit for the period or, where appropriate, minus the loss for the period. By the same token, net worth could be equal to the accumulated shortfall plus the actuarial losses for the period or, where applicable, minus the profit for the period.

The changes in the balance sheet account records which are the changes in the value of assets and liabilities in the course of the accounting period and the aggregated amounts recorded in the various accumulation accounts; in fact, this is the definition of the income statement which quantifies the solvency changes by means of the difference in the net worth of the system. 


\section{2.-The income statement for a fictional already-functioning NDC scheme combining retirement and disability contingencies with a MPB.}

In this subsection we develop the main entries for the income statement for a hypothetical already-functioning NDC scheme combining retirement and disability contingencies with a MPB. This profit and loss account follows the model published by the Swedish authorities, but some modifications need to be introduced in order to adapt it to the specific NDC model proposed in our paper. Our proposed income statement incorporates an important item which the benchmark model should include to better compute the annual change in the system's net worth.

It should be noted that the "Swedish approach" is an adaptive methodology with an annual review process, therefore it is not prospective or predictive, and the assumption that the system's rules and the economic and demographic conditions prevailing at the time of the valuation remain constant is fully coherent.

As anyone can easily see, the ABS and the income statement are closely linked. In fact, the "net profit" for a period can be computed without an income statement. The simplest manner to determine the change in the system's net worth is by comparing the opening and closing ABS; but there is a significant lack of detail.

The proposed income statement structure is shown in Table 3, in which for simplicity's sake it is assumed that NCRs are totally guaranteed by the sponsor, the system's administration costs are financed by general taxation and that inheritance gains arising and distributed and are perfectly matched within the year.

Table 3 exhibits on the left side changes in assets, which are interpreted in the following manner: A negative item (-) decreases the asset and a positive item (+) increases it, by the amount shown. On the right side, we find the changes in pension liabilities; its associated items need to be interpreted in the following manner: A negative item (-) decreases the pension liability and a positive item $(+)$ increases it, by the amount shown.

\begin{tabular}{|c|c|}
\hline \multicolumn{2}{|c|}{$\begin{array}{c}\text { Table 3: The Income Statement for a NDC scheme combining Retirement and } \\
\text { Disability contingencies with a MPB for the period. }\end{array}$} \\
\hline FUND ASSETS (Changes) & LIABILITIES (Changes) \\
\hline Pension contributions: C & New pension credit: C \\
\hline Sponsor contributions for NCRs: SC & Recognition of NCRs: R \\
\hline Pension disbursements: - PT & Pension disbursements: - PT \\
\hline Net return on funded capital: D & Indexation: I \\
\hline CONTRIBUTION ASSET (Changes) & Value of change in life expectancy: $\delta$ e \\
\hline $\begin{array}{c}\text { Value of change in contribution revenue: } \\
\delta \text { C }\end{array}$ & Value of change in discount rate: $\delta$ G \\
\hline $\begin{array}{c}\text { Value of change in turnover duration: } \\
\text { Total Debit Side }\end{array}$ & NET GAIN/LOSS \\
\hline \multicolumn{2}{|c|}{ Source: Own. } \\
\hline
\end{tabular}

Beginning on the left side first, the annual change in fund assets or buffer fund is the result of adding the income from all types of contributions to the return on funded capital and deducting the payments for retirement and disability pensions. In this scheme there could be two types of contributions, firstly, the ordinary one which is made by affiliates, and secondly the extraordinary one which is made by the sponsor to cover NCRs. 
The extraordinary contribution (if necessary) for each new beneficiary is determined in the following way: in the event of disability or retirement, firstly the amount required for awarding the MPB is calculated using a gender-neutral annuity factor. This amount is then compared to the individual pension balance; if the amount calculated is less than the amount accredited in the notional account, the sponsor has to top up the difference ${ }^{12}$.

Pension contributions are used to pay beneficiaries (disabled and retirees) in the same year. In practice, all pension contributions are paid and distributed monthly to the reserve fund. The surpluses or deficits that arise when pension contributions are greater or less than pension disbursements are absorbed by the buffer fund. Finally, the net return on funded capital includes dividends on assets held by public pension funds, financial assets are valued at their market price on the last trading day of the year. The net return on funded capital can be positive or negative depending on the situation of the financial markets.

On the left side, we can also see the changes to the contribution asset broken down into contribution revenue and turnover duration. The value of the change in contribution revenue is the monetary value, in terms of how much more (or less) liability can be financed by a higher (or lower) level of contributions relative to the preceding year.

The value of the change in $T D$ (volume of assets) is a combined effect from a variety of causes. This amount synthesizes into a single number a great deal of information about the system's rules, the age distribution of the population, the age patterns of the labour supply and earnings, mortality (change in life expectancy) and disability rates (change in biometrics assumptions).

The first item that we can see on the right side is the new pension credits. This accounting item should be identical to income from contributions; the equality between contributions paid and new pension credits is a key feature of a pure NDC scheme. In practice, both items could be slightly different due to operative reasons.

The second item on this side is the so-called "recognition of NCRs"; apart from certain demographic and economic circumstances, its annual amount will depend on the criteria chosen to quantify the NCRs. Its countepart on the debit side is sponsor contributions for NCRs. Both amounts should be perfectly matched and correspond to the redistributive part of the scheme. This entry would include the effect of legislative reforms affecting the minimum pension benefit level. This entry cannot be found in the benchmark model.

The liability is reduced by the amount of pension expenses, given that pension payments are an amortization of the pension liability. On both sides of the income statement, the amount of the pension disbursements should coincide.

Change in pension liabilities due to indexation of notional accounts and benefits in payment, I, are also accounted for. It is assumed that the indexation rules are the same for the actuarial part and for the benefits originated from NCRs. In our model the notional rate of return is the wage bill growth. If the system had implemented an $\mathrm{ABM}$, and it were triggered because the balance ratio (see Appendix 1) fell below 1.0000, then the real indexation would be lower than the wage bill growth.

The entry "Value of change in life expectancy", $\delta \mathbf{e}$, is due to the annual update of life expectancy. The increase in life expectancy over the past several decades has been striking and represents a key challenge for SSSs. This item is in coherence with the

${ }^{12}$ This method is similar to that used in Chile for disability insurance (Edwards et al., 2015). In fact, the sponsor is the insurer of the system. 
accounting principle of updating main data on an annual basis. It is important to accurately estimate the life expectancy for the two collectives: disabled and retired people. Mortality (life expectancy) for disabled people depends on the cause (e.g. accident versus sickness) and severity (partial versus total, temporary versus permanent) of disability (Plamondon, et al., 2002; Pitacco, 2014)

To give a couple of examples, in Canada, mortality of disability beneficiaries is much greater than that of the general population. Mortality rates of disability beneficiaries aged 50 to 64 in 2011 are on average six times higher than that of the general population. For a 50-year-old disability beneficiary, the level of mortality is about equal to that of an individual aged 75 in the general population (OSFIC, 2015). In the US, the mortality rate for a female (male) disabled beneficiary is 4.3 (5.02) times that of a healthy annuitant. For a 50-year-old female (male) disability beneficiary, the level of mortality is almost equal to that of an individual aged 69 (72) in the population of healthy pensioners ${ }^{13}$ (SOA, 2014).

In short, disabled people have a lower life expectancy than active people, but the difference in longevity tends to decrease notably as the individuals increase in age.

In contrast to the Swedish model, on the right side we have included another item known as the "value of change in the discount rate $(G)$ ”, $\delta \mathbf{G}$. The discount rate assumption is the most influential actuarial input affecting both funding ratios and contribution requirements (Chen and Matkin, 2017). In our model it does not affect the level of contributions but it is very important to value pensions in payment and to compute the balance ratio. Either way, its effect on the ABS would be dampened by using a 5-year moving average of the wage bill growth, or another reasonable form of smoothing.

The main practical implication of the introduction of this item is that it would increase the volatility of the system's results and could trigger a greater number of times the automatic balance mechanism.

Finally, a net income or loss for the year is accounted for on the right side.

From an analytical point of view, the change in net worth can be detailed as follows:

$$
\begin{gathered}
\underbrace{\delta N W_{t}^{S}=N W_{t}^{S}-N W_{t-1}^{S}}_{\text {Changes in net worth }}=\delta A_{t}^{S}-\delta V_{t}^{S} \\
\overbrace{(\overbrace{\left.A_{t}^{S}-A_{t-1}^{S}\right)}^{\text {Assets }})-(\underbrace{\left.V_{t}^{S}-V_{t-1}^{S}\right)}_{\text {Liabilities }}}^{\text {Changes }} \\
\overbrace{\text { Changes }}^{\text {Shang }} \underbrace{\delta B F_{t}^{S}}_{\text {Fund asset }}+\underbrace{\text { SCA } A_{t}^{S}}_{\text {Contribution asset }}-V_{t}^{S}
\end{gathered}
$$

\footnotetext{
13 Similar results can be found in other countries such as Norway, Sweden (Gjesdal et al., 2009). South Korea (Park et al., 2017), Belgium or Spain (Duran et al., 2016).
} 
As depicted in formula [1.], the change in net worth can be determined in the simplest manner by comparing the system's assets and liabilities on two consecutive valuation dates.

If $\delta N W_{t}^{S}>0 \Rightarrow P_{t}^{S}$, the change in net worth is positive, i.e. the sum of the left side items exceeds the sum of the right side items in value, in short the system has actuarial profits for the period.

If $\delta N W_{t}^{S}<0 \Rightarrow L_{t}^{S}$, the sum of the right side items exceeds the sum of the left side items, shows that the net wealth has been reduced, i.e. the system has actuarial losses for the period.

If $\delta N W_{t}^{S}=0$, the system's net worth does not change.

The changes in net worth can be broken down into three main items:

1.- Change in fund/financial asset

$$
\delta B F_{t}^{S}=C_{t}^{S}+{ }^{N C R} S_{t}^{S}-P T_{t}^{S}+r_{t} \cdot B F_{t-1}^{S}
$$

Where, $C_{t}^{S}$ : is the income from ordinary contributions; ${ }^{N C R} S_{t}^{S}$ : is the income from sponsor contributions for NCRs; $P T_{t}^{S}$ : is the total pension disbursements, and $r_{t} \cdot B F_{t-1}^{S}$ : is the net return on funded capital.

2.-Change in contribution asset:

$$
\begin{aligned}
& \delta^{N D C} C A_{t}^{S}={ }^{N D C} C A_{t}^{S}-{ }^{N D C} C A_{t-1}^{S}=\overbrace{\delta C_{t}^{S}}^{\text {Revenue effect }}+\underbrace{\delta T D_{t}^{S}}_{\begin{array}{c}
\text { Turnoverduration } \\
\text { effect }
\end{array}} \\
& = \\
& \overbrace{\left(\left(C_{t}^{S}-C_{t-1}^{S}\right) \cdot \frac{\left(T D_{t-1}^{S}+T D_{t}^{S}\right)}{2}\right)}^{\delta C_{t}^{S}}+(\underbrace{\frac{\left(C_{t}^{S}+C_{t-1}^{S}\right)}{2} \cdot\left(T D_{t}^{S}-T D_{t-1}^{S}\right)}_{\delta T D_{t}^{S}})
\end{aligned}
$$

If the approach adopted to back up the increase in liabilities due to the introduction of an MPB was the public contribution asset method, we would also need to take into account the annual change in public contribution asset.

3.-Change in pension liability:

$$
\delta V_{t}^{S}=C_{t}^{S}+{ }^{N C R} R_{t}^{S}-P T_{t}^{S}+I_{t}^{S}+\overbrace{\delta e_{t}^{S}}^{\begin{array}{c}
\text { Life expectancy } \\
\text { effect }
\end{array}}+\underbrace{\delta G_{t}^{S}}_{\begin{array}{c}
\text { Discount rate } \\
\text { effect }
\end{array}}
$$

Where, ${ }^{N C R} R_{t}^{S}$ : is the value of newly awarded NCRs; $I_{t}^{S}$ : is the indexation effect; $\delta e_{t}^{S}$ : is the value of the change in the liability to pensioners due to changes in life expectancy: and $\delta G_{t}^{S}$ : is the value of the change in liability to pensioners due to changes in the discount rate.

The value of the change in the liability to pensioners due to the updated information about the discount rate and the life expectancy can be expressed as follows: 


$$
\begin{aligned}
& \text { Liability to pensioners } \\
& \text { with updated information } \\
& \overbrace{P e n_{-}(s)_{t}^{u i}} \quad-\underbrace{P e n_{-}(s)_{t}^{n u i}}_{\text {Liability to pensioners }}=\delta e_{t}^{S}+\delta G_{t}^{S} \\
& \text { with non-updated information } \\
& = \\
& \text { Liability with }
\end{aligned}
$$

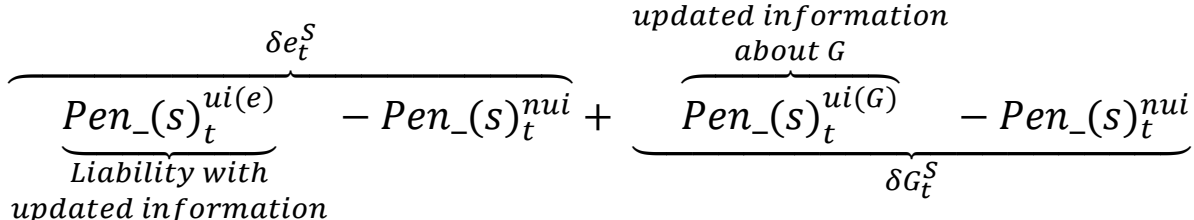

Finally, the income statement could easily be disaggregated by contingency, in formulas [1.] to [5.], we only need to change the superscript " $S$ " by " $R$ " or " $D$ " where necessary.

$$
\delta N W_{t}^{S}=\delta N W_{t}^{D}+\delta N W_{t}^{R}
$$

\section{3.-Why the income statement of a hypothetical already-functioning NDC is important from a public accounting perspective.}

Now that we have presented the Income Statement for our model, we consider it appropriate to dedicate some space to explain its importance for PAYG pension systems (in general) and for NDCs schemes in particular.

We are aware that the public sector's financial reporting mechanisms do not have to coincide with those of the private sector given that the main objective of both systems is different.

In the case of the public sector pension system, its principal objective is not as a profit making entity and as previously considered the pension and disability policies have multiple implications for society, which go beyond the objective of this paper.

However, we are dealing with the pension contributions of individuals and there needs to be responsibility for the correct management of these sums, the sustainability of the system and the financial information reported should be useful to user's needs, for future decision making.

The above affirmation coincides with the standard setter objectives for the public sector, for example the IPSASB (2017c) set out the requirements for general purpose financial reports in the public sector and the public sector pension system clearly enters into the entities covered by their standards.

The reporting of an Income Statement also coincides with the objectives of IPSAS 1 Presentation of Financial Statements (IPSASB, 2017a) using accrual based accounting methods. This standard outlines that the objectives of general purpose financial reporting in the public sector should be to provide useful information for decision-making purposes and to demonstrate the accountability of the entity for the resources entrusted to it.

The latter is very clear on the objective of the accountability of the resources in the pension scheme regardless of the public policy taken for contribution collection and its distribution. In order to accomplish this aim the standard mentions, among others, the provision of aggregate information that is useful in evaluating the entity's performance in terms of service costs, efficiency and accomplishments. This would justify the preparation of an income statement. 
IPSAS 1 (IPSASB, 2017a) states that, general purpose financial statements can also have a predictive role or a prospective role, providing information which is useful in predicting the level of resources required for continued operations, the resources that may be generated by continued operations and the associated risks and uncertainties ${ }^{14}$. The above distinctly covers the objective of reporting the sustainability and solvency of the pension system.

The standard also considers that a complete set of financial statements will comprise of a statement of financial position which is what has been denoted to as the balance sheet; a statement of financial performance, referred to in our paper as an income statement; a statement of changes in net assets/equity; a cash flow statement; budgeted and actual amounts when the entity makes available its approved budget; notes to the accounts and comparative information for the preceding period.

As already mentioned above, the inclusion of the Income Statement in our version uses the TSPS (2018) as a benchmark and extends the previous model developed by PérezSalamero at al. (2017) and Vidal-Melia et al. (2018) by incorporating an Income Statement.

The inclusion of an Income Statement into the published information relating to the Public Pension System of a country could improve the understanding of the information and also advance in the transparency of the system. Of course, the change in the net worth can be determined by calculating the difference in this item from the closing and opening Balance sheet for the reporting period but an Income statement shows a breakdown of that change in net worth during the period.

In the public system model, the income statement has the role of identifying the changes over the period being reported. These changes are broken down into sub classifications and by contingencies, which enable us to distinguish the effect of modifications in each part of the system.

The changes can be contemplated in Table 3, it includes items considering variations in the number of affiliates in the system, or changes in the mortality rates at retirement age, the probabilities of becoming disabled etc. which eventually lead us to the calculation of the needs for sponsor support, the buffer reserve or the necessity of triggering the automatic balance mechanism if it were implemented in the system.

In effect, the income statement offers more detailed information regarding changes in the system and helps stakeholders and management to take informed decisions. In a private organisation, the financial health of the business is assessed through the income statement. The financial information can be prepared for reporting periods that are convenient for management and this allows them to compare and interpret the information with previous weekly or monthly reports, year to date or previous years comparative information. All changes can be interpreted and explained, which will help to foresee problem areas for the future, areas that need to be monitored more closely and to examine whether significant variances are once off or whether it is necessary to incorporate them into future budgets.

Traditionally the public sector has relied on pure cash accounting. However, Public Pension systems prepared using the accruals accounting basis have the advantage of being

\footnotetext{
${ }^{14}$ Our model is not a prospective one. For this approach we would have to work in a "budgetary" way, i.e. with explicit projections. Future research could deal with this issue.
} 
able to see the complete picture by including the assets and liabilities of all components of the system at a particular moment in time improving decision making for the future.

This could be beneficial for pension system affiliates in order to assess to what extent pension promises are reliable and to take decisions in the future when exercising their right to vote. However, by changing their voting options does not guarantee an improvement in the pension system given that a new political party may not fulfil its promises either. It does however give affiliates more information, which they can use as a tool to manifest their thoughts and priorities in relation to a change in the system. It also makes the system more transparent.

Presently in Continental Europe, which uses a distribution method rather than a capitalisation method for pension systems gives an affiliate even less possibility to change the conditions than in the Swedish system. An increase in transparency, which could lead to a change in voting options, has less impact because it does not commit future governments to the interest of affiliates or even to a guarantee to contributions already accumulated by them in the system.

It is a timely opportunity to consider the incorporation of financial pension reports prepared according to the accrual basis of accounting as we have public accounting standards that provide a solid base of guidance in relation to the objective of the information, the content of the reports and the application of valuation measurements.

The accrual model allows for planification for the future and changes can be identified from comparative figures. The Swedish model takes into account the obligations of the system at a particular date and its corresponding future contributions at that point.

In an article by de Haan et al. (2012) they consider that a model based on Projected Benefit Obligations (PBO) would be more fruitful than the accrual model. We totally agree that projected information is fruitful and necessary but principally for the management of the system and for taking internal decisions but the accrual method provides very clear information for the general needs of users taking into account the facts on the reporting date.

The IPSAS 1 (IPSASB, 2017a) also includes budgeted and actual information as part of a complete set of financial information. PBO's could therefore be included in future budgeting information.

IPSAS 1 also takes into consideration the fundamental objective of the information being reported. It clearly states that financial statements shall present fairly the financial performance corresponding to the statements being reported. It explains that Fair presentation (FP) requires the faithful representation of the effects of transactions, other events, and conditions in accordance with the definitions and recognition criteria for assets, liabilities, revenue, and expenses set out in IPSASs (IPSASB, 2017b). The application of IPSASs (IPSASB, 2017b), with additional disclosures when necessary, is presumed to result in financial statements that achieve a fair presentation. This fair presentation is an alternative term, not always considered identical in the literature, used for the previously mentioned TFV. It is the incorporation of a term that requires these reports to show information that can be confided in.

As previously mentioned, Boado-Penas et al. (2008) pointed out that the main aim of the ABS is to give a TFV of the pension system's assets and liabilities at the beginning and end of the fiscal year. We add to this affirmation by indicating that an Income statement has as its main objective the provision of a TFV/FP of the changes in the net worth of the 
pension system over a period of time classified into elements which are useful for information purposes.

The incorporation of an Income Statement is another step in the improvement of Public Pension Reporting. We are presently at an early stage and future research will develop this information and make it more useful for stakeholders and especially policy makers as time moves on. A further step to increasing transparency and information needs could be done by complementing the Balance sheet and the Income Statement with a Cash Flow Statement as is done for Financial Reporting in the private sector. This will provide detail as to where the inflows and outflows of cash are occurring and also coincides with the objectives of IPSAS 1 on Presentation of Financial Statements (IPSASB, 2017a). More specifically, IPSAS 1 specifies that accountability can be obtained by reporting on the source, allocation and uses of financial resources, by reporting on how activities were financed and how its cash requirements were met among other possibilities.

Our model, which takes the Swedish model as a base is a step forward because it, also, incorporates the changes for disability pensions, the value of change in the discount rate and the explicit recognition of NCRs into the Income statement.

In our opinion, improving the reporting mechanisms of pension reporting is essential without losing sight of the social objectives of the system. We believe there is moral duty to manage correctly pension contributions by affiliates and taxpayer contributions in order to obtain benefits for the population as a whole.

We also believe that the main objective of the inclusion of an Income statement is to provide a TFV/FP of changes in the pension system over a period including them sub classified into more understandable and useful information than by just showing the difference in the net worth of the system from the balance sheet.

\section{4.-NUMERICAL ILUSTRATION.}

This section shows a numerical example representative of the model developed above. The numerical example is presented to make it easier for the reader to understand how the proposed model for financial reporting functions and what its main advantages and disadvantages are. To be more specific, the exercise, which should be viewed simply as an illustration, shows the annual changes in the system's financial position via the income statement for a fictional already-functioning NDC pension system. The proposed scheme is not in operation in any country as yet.

The starting point is the ABS of the scheme at the end of years $t-1$ and $t$ (Table 4). The system incorporates an MPB equivalent of $25 \%$ of the system's average wage ( $\left.N D C_{d r}^{25 \%}\right)$ Changes in net worth are determined by comparing the system's assets and liabilities in these consecutive accounting periods. The table also shows the TD for the system, $\boldsymbol{T} \boldsymbol{D}_{\boldsymbol{t}}^{\boldsymbol{S}}$, and by contingency $\left(\boldsymbol{T} \boldsymbol{D}_{t}^{R} ; \boldsymbol{T} \boldsymbol{D}_{t}^{D}\right.$ ), the balance ratio, $\boldsymbol{B} \boldsymbol{R}_{t}^{S}$, (calculated without taking into account the part of the buffer fund corresponding to the sponsor's support), the degree of funding, $\boldsymbol{D} \boldsymbol{F}_{\boldsymbol{t}}$, (the buffer fund divided by the pension liability of the system) and the liability structure ratio, $\boldsymbol{L} \boldsymbol{S}_{\boldsymbol{t}}$, (the ratio between the liabilities to contributors and total liabilities).

At the end of year $t-1$ the system's financial position is sound, since the balance ratio is greater than one (1.014), i.e. the accumulated surplus is positive. In general terms it can be said that this particular system is reasonably solvent, and that therefore at the date of the report the participants (contributors and pensioners) should have a realistic expectation of receiving the benefits that have been accrued, without the system's sponsor 
(the state) having to make any extraordinary contributions (except for future NCRs). Such a statement is made on the assumption that the system's rules and the economic and demographic conditions prevailing at the time of the valuation remain constant.

As can be seen in Table 4, the degree of funding for this system is clearly positive (16.11\%), mainly due to sponsor support and because the approach adopted to back up the increase in liabilities due to the introduction of a MPB is the buffer fund method. Therefore, the higher the level of the NCRs, the higher the degree of funding.

Table 4: The ABS of a $N D C_{d r}^{25 \%}$ scheme at the end of years t-1 and $t$ with changes in net worth (monetary units)

\begin{tabular}{|c|c|c|c|}
\hline Items/year & $t-1$ & $t$ & Variation \\
\hline \multicolumn{4}{|c|}{ Assets } \\
\hline BF & 11.500 & 11.730 & 0.230 \\
\hline BF_(R+D)_NCR & 5.500 & 5.588 & 0.088 \\
\hline CA_(R) & 80.120 & 81.963 & 1.843 \\
\hline CA_(D) & 19.880 & 20.079 & 0.199 \\
\hline Ad_(R+D) & 0.000 & 0.000 & 0.000 \\
\hline L_(R+D) & 0.000 & 0.000 & 0.000 \\
\hline Total & 117.000 & 119.360 & 2.360 \\
\hline \multicolumn{4}{|c|}{ Liabilities and sponsor support (capital) } \\
\hline Ss_(R+D) & 10.000 & 10.000 & 0.000 \\
\hline Con_(R) & 55.510 & 56.620 & 1.110 \\
\hline Con_(D) & 12.260 & 12.505 & 0.245 \\
\hline Pen_(R) & 24.610 & 24.856 & 0.246 \\
\hline Pen_(D) & 7.620 & 7.772 & 0.152 \\
\hline Pen_(R)_NCR & 2.200 & 2.222 & 0.022 \\
\hline Pen_(D)_NCR & 3.300 & 3.366 & 0.066 \\
\hline As_(R+D) & 1.500 & 1.500 & 0.000 \\
\hline P_(R+D) & 0.000 & 0.518 & 0.518 \\
\hline Total & 117.000 & 119.360 & 2.360 \\
\hline \multicolumn{4}{|c|}{$\begin{array}{l}\text { Solvency, funding and liability structure indicators } \\
\end{array}$} \\
\hline $\begin{array}{c}T D_{t}^{S} \\
\left(T D_{t}^{R} ; T D_{t}^{D}\right)\end{array}$ & $\begin{array}{c}31.92 \\
(34.03 ; 25.55)\end{array}$ & $\begin{array}{c}31.60 \\
(34.37 ; 23.78)\end{array}$ & -0.3192 \\
\hline$B R_{t}^{S}$ & 1.014 & 1.019 & 0.0046 \\
\hline$D F_{t} \%$ & 16.11 & 16.13 & 0.0002 \\
\hline$L S_{t} \%$ & 64.24 & 64.40 & 0.0016 \\
\hline
\end{tabular}

At the end of year t the system's ABS reports a better financial position (1.019) than in the previous accounting period, given that for this period the system registers actuarial profits (0.519). In this situation, the accumulated surplus becomes larger, i.e. the change in net worth is positive. As anyone can see, in this accounting period the system has recorded profits because the difference between the variation in assets (2.360) and liabilities (1.842) is positive (0.518). The detailed changes in the system's financial position by contingencies are shown on the income statement (Table 5). The study of this statement is the real novelty of this paper and enables us to deepen the analysis into the reasons behind the changes in the system's solvency by type of benefit. 
What first draws our attention in this income statement is that for this period the disability contingency registers losses (0.125) whereas the retirement contingency records profits (0.643). Expenditure on disability pensions is at around $26.15 \%$ of pension disbursement. As already stated, we do not reclassify pensions once they are in payment as this would prevent them from correctly determining the actuarial result by contingency. This makes sense from an actuarial point of view and enhances transparency.

The system has a cash flow surplus because income from contributions plus sponsor contributions for NCRs is in excess of pension outlays. This excess is accumulated in the buffer fund, and the positive return on funded capital increases the fund asset at the end of the accounting period. This is also true if we examine the change in fund assets by contingency.

\begin{tabular}{|c|c|c|c|}
\hline Table 5: The income statement for the period t-1, t (monetary units) \\
\hline ITEMS & System & $\mathbf{R}$ & $\mathbf{D}$ \\
\hline FUND ASSET (Changes) & $\mathbf{0 . 3 1 8}$ & $\mathbf{0 . 1 9 7}$ & $\mathbf{0 . 1 2 1}$ \\
\hline Pension contributions & 3.229 & 2.385 & 0.844 \\
\hline Sponsor contributions for NCRs & 0.088 & 0.022 & 0.066 \\
\hline Pension disbursements: & -3.164 & -2.337 & -0.827 \\
\hline Net return on funded capital & 0.165 & 0.127 & 0.038 \\
\hline CONTRIBUTION ASSET (Changes) & $\mathbf{2 . 0 4 2}$ & $\mathbf{1 . 8 4 3}$ & $\mathbf{0 . 1 9 9}$ \\
\hline Value of change in contribution revenue & 3.057 & 1.036 & 2.021 \\
\hline Value of change in turnover duration & -1.015 & 0.806 & -1.822 \\
\hline Total LEFT SIDE & $\mathbf{2 . 3 6 0}$ & $\mathbf{2 . 0 4 0}$ & $\mathbf{0 . 3 2 0}$ \\
\hline LIABILITIES (Changes) & $\mathbf{1 . 8 4 2}$ & $\mathbf{1 . 3 9 7}$ & $\mathbf{0 . 4 4 5}$ \\
\hline New pension credit & 3.229 & 2.385 & 0.844 \\
\hline Recognition of NCRs & 0.088 & 0.022 & 0.066 \\
\hline Pension disbursements & -3.164 & -2.337 & -0.827 \\
\hline Indexation & 0.900 & 0.720 & 0.180 \\
\hline Value of change in life expectancy & 0.030 & 0.010 & 0.020 \\
\hline Value of change in discount rate & 0.759 & 0,597 & 0,162 \\
\hline NET WORTH (change) & $\mathbf{0 . 5 1 8}$ & $\mathbf{0 . 6 4 3}$ & $\mathbf{- 0 . 1 2 5}$ \\
\hline Total RIGHT SIDE & $\mathbf{2 . 3 6 0}$ & $\mathbf{2 . 0 4 0}$ & $\mathbf{0 . 3 2 0}$ \\
\hline
\end{tabular}

Source: Own.

NB: The totals will not necessarily equal the sums of the rounded components.

The ratio between (total) pension contributions and (total) pension disbursements is approximately $104.82 \%$, so the system has a treasury surplus that amounts to $4.82 \%$ of the aggregate income from contributions.

Changes in the contribution asset add net worth to the system (2.042), but the value of the change in the system's turnover duration decreases the asset by the amount shown (1.015). Nevertheless, the value for the retirement contingency is positive, given that its associated TD is slightly higher in $t$ (34.37) than in $t-1$ (34.03).

The analysis of changes in liabilities shows that the pension liability increases mainly with the annual indexation of pensions in payment and pension account balances (0.90), and the value of change in the discount rate (0.759). The annual changes of both items are determined by the change in the growth of the notional rate " $G$ ". However, the effect on the pension liability works in the opposite direction.

The higher the growth of the annual notional rate, the higher the pension liability due to the indexation mechanism. Obviously, for the item "value of change in discount rate" the 
higher the growth of the annual notional rate used for valuing pensions in payment, the lower the pension liability. In this numerical example, this item increases the pension liability because the discount factor used is slightly lower than in the previous accounting period. In practice, to achieve a more accurate fair presentation in this income statement, the most suitable option for an already-functioning NDC scheme would be to use an estimated value of $G$ based on the most recently observed data (the previous 3 or 5 years). This is in keeping with the principle that assets and liabilities are valued mainly on the basis of events and transactions that are verifiable at the time of valuation.

In the Swedish System, for calculating the liability to pensioners, the initial pension of each cohort is multiplied by the economic annuity divisor (ED), which corresponds to an actuarial discount factor weighted by the number of pensioners with their respective pensions and with a technical interest rate of 1.6 percent, i.e., the assumed annual real growth rate for the income index (Vidal-Meliá et al., 2010; TSPS, 2018). This discount rate has remained unchanged since the inception of the system. Here a clear policy implication emerges, (Settergren, 2013) given that the procedure of fixing the discount rate over time seeks to maximize the stability of the solvency ratio. In practice, the introduction of a change in this item would increase the volatility of the system's results and could trigger the ABM with more frequency.

On the other hand, ignoring a change in this item by the Swedish authorities cannot be considered as appropriate from a fair presentation of the financial statements point of view. According to Palmer and Könberg (2019), during 2002-2017 real income growth per capita grew at an average rate of 2.1 percent, i.e., 0.5 percent per year above the 1.6 percent applied in the actuarial factor used for computing the liability to pensioners. If the annual real income growth rate had to be used to calculate liabilities to pensioners, the net worth changes originally estimated would have been (very) different from those reported by the Swedish authorities; and what is more important, the ABM would not necessarily have been activated and/or the timing of triggering would have been different.

We should bear in mind that a retrospective accounting exercise would be needed to respond properly to the above suggested issues about the Swedish NDC pension scheme.

To conclude with the brief analysis of this illustrative exercise, it can be seen that the value of the change in life expectancy also increases the pension liabilities for retirees. The pension liability for active workers is unaffected by changes in mortality. This accounting model demands periodic updates of the life expectancy data for both collectives, i.e., periodic (static) mortality tables need to be frequently released. The use of mortality generational tables may introduce more instability in a pension institution's accounts than periodic tables ${ }^{15}$. For the disability contingency, the value of the change in life expectancy assumptions shows a positive amount of 0.02 monetary units, which leads to an increase in disability pension liabilities.

Finally, as in any double-entry accounting system, the net income or loss (change in net worth, 0.518 units in this example) equals the difference between the change in assets and the change in liabilities.

\footnotetext{
${ }^{15}$ It has been demonstrated, Arnold- Gaille et al. (2019), that institutions that use mortality tables including future mortality evolution will most likely need to make more important adjustments (positive or negative) to their liabilities than institutions using periodic (static) tables whenever a new table is released.
} 


\section{CONCLUDING COMMENTS AND FUTURE RESEARCH}

This paper is in line with the ongoing debate on how to recognize and measure assets and liabilities of SSSs. This paper looks into the methodology labelled as "Swedish" open group developed for measuring liabilities and assets in contributory SSSs; the most relevant features are identified and compared to the traditional approaches and a literature review is also provided. In the literature, little attention has been paid to the SOG approach, so, the first contribution of this paper is to fill this gap. It is at least surprising that in a recent special issue of an international journal which addressed the topic of the actuarial and financial reporting of SS obligations, none of the published papers referred to this approach.

The SOG approach has two relevant positive features. On the one hand, the way of measuring the system's assets and liabilities has a high degree of transparency and needs no complicated projections of economic, financial or demographic variables, which could easily have a biased effect on the sustainability and solvency indicators. On the other hand, this approach is suitable to introduce automatic balance mechanisms (ABMs,) given that the possibly endless debates as to the accuracy of long term projections are avoided.

The paper has developed a full accounting model for monitoring the solvency of a notional defined contribution (NDC) pension scheme with disability and minimum pension benefits; this is considered to be the second contribution. In line with the principle of separating the distributional aspects of social policy from the contributory aspect of the NDC scheme, the proposed model splits the system into two parts: the pure NDC part and the redistributive part, which includes the assets and liabilities originating from NCRs.

To be more specific, using the annual report of the Swedish pension system as a benchmark (TSPS, 2018), we have extended the "Swedish" actuarial balance sheet developed by Pérez-Salamero et al. (2017) by adding an income statement which fully explains the reasons behind the changes in the system's solvency by type of benefit. This paper has developed the most realistic case for an already-functioning NDC scheme and presented the technical details of the model, which makes it possible to integrate disability and minimum pension benefits within the NDC framework.

Another valuable contribution is that the paper has highlighted the importance of disability within the contributory SSSs and the fact that disability costs need to be closely monitored; our paper covers this existing gap in the NDCs literature. The link between disability and NDC schemes is not a minor issue. The paper analyses how disability benefits are treated within the NDC framework and its relation with minimum pension benefits. It has been detected that there are several issues to be improved: discontinuities in benefit levels which occurred when disability benefits are converted into retirement benefits at the ordinary retirement age, the "system" gives incentives to become disabled before obtaining the retirement pension, the formula used to calculate the disability pension does not provide a clear link between benefits and contributions, a lack of transparency can be observed in the redistribution embedded in the defined benefit formula used to calculate disability benefits, and the specific life expectancy of the disabled people by age is not used to compute the disability benefit, which is surprising from an actuarial point of view.

The example we develop adds value to the paper because it sheds light on the main differences between our proposal and the benchmark model which only includes the retirement contingency and doesn't account for the NCRs. Furthermore, the example 
clearly shows that this accounting framework integrates both contributory and social aspects of public pensions and discloses the real cost of the disability contingency and the redistribution through minimum pensions.

With regard to the question asked in the title of this text, solid reasons have been given which highlight the importance of the pension system's income statement and stress the need for presenting it annually for PAYG pension systems (in general) and for NDCs schemes in particular. The income statement offers more detailed information regarding changes in the system and helps stakeholders and management to take informed decisions, it is useful in evaluating the entity's performance in terms of service costs, efficiency and accomplishments. The income statement can also be useful in predicting the level of resources required for continued operations, the resources that may be generated by continued operations and the associated risks and uncertainties.

Last, but not least, our proposed income statement could serve as a guidance to improve the true and fair view of the Swedish actuarial balance sheet through a better determination of the changes in the system's net worth.

To conclude, on the basis of the model presented in this paper and its associated numerical example; at least three important directions for future research can be identified.

First, on the theoretical side, the use of the income statement in other models and a further step to increasing transparency and information needs could be achieved by complementing the Balance sheet and the Income Statement with a Cash Flow Statement as is done for Financial Reporting in the private sector. The preparation of what is considered to be a full set of financial statements by the IPSASs has to be the objective of all accruals based systems in the short term.

The second direction would be on the applied side. In the Swedish System, for calculating the liability to pensioners, the initial pension of each cohort is multiplied by the economic annuity divisor (ED), which corresponds to an actuarial discount factor weighted by the number of pensioners with their respective pensions and with a fixed technical interest rate. This discount rate has remained unchanged since the inception of the system. In our opinion this practice cannot be considered as the most appropriate from a fair presentation point of view when more accurate information is available. It would be interesting to perform a retrospective accounting exercise using the annual real income growth rate to calculate liabilities to pensioners. The main aim of the proposed exercise would be to compute if the net worth changes estimated by the Swedish authorities would have been different from those originally reported using an updated discount rate; and what is more important, if the ABM would have been activated in the same years.

Finally, a third direction would consist of designing a different ABM in coherence with the introduction of the item "Value of change in the discount rate" into the income statement. Given that its introduction would increase the volatility of the system's results and could trigger the automatic balance mechanism more frequently; which would also cause greater instability in pensioner's benefits. The new ABM would be in the line of setting a no-action range for the balance ratio in order to avoid an excessive number of triggers. If the solvency indicator fell outside this range, the ABM could restore itself to within the no-action range. 


\section{6.-REFERENCES}

AAA (American Academy of Actuaries). (1998). “Actuarial Standard of Practice No. 32, Social Insurance" Committee on Social Insurance of the American Academy of Actuaries.

AAD (Actuarial Affairs Division). (2017). "Summaries of the 2014 Actuarial Valuation and Reform Options.” Pension Bureau, Ministry of Health, Labour, and Welfare, Tokyo.

Alonso-García, J. and P. Devolder (2019). Continuous time model for notional defined contribution pension schemes: Liquidity and solvency. Insurance: Mathematics and Economics, https://doi.org/10.1016/j.insmatheco.2019.06.001

Armour, P. (2018). The Role of Information in Disability Insurance Application: An Analysis of the Social Security Statement Phase-In. American Economic Journal: Economic Policy, 10 (3): 1-41.

Arnold, S., Jijiie, A., Jondeau, E. and Rockinger, M. (2019). Periodic or generational actuarial tables: which one to choose? European Actuarial Journal. https://doi.org/10.1007/s13385-019-00198-x.

Arnold-Gaille, S., Boado-Penas, M.C. and H. Godinez-Olivares. (2016). Longevity Risk in Notional Defined Contribution Pension Schemes: A Solution. Geneva Papers on Risk and Insurance Issues and Practice. 41(1): 24-52.

Arthur, W.B. and McNicoll, G. (1978) Samuelson, population and intergenerational transfers, International Economic Review. 19(1): 241-246.

Autor, D., and M. C. Duggan. (2006). The Growth in the Social Security Disability Rolls: A Fiscal Crisis Unfolding. Journal of Economic Perspectives. 20(3): 71-96.

AWG (2018a), Ageing Working Group. Polish country fiche on pension projections 2018. https://ec.europa.eu/info/publications/economy-finance/2018-ageing-reporteconomic-and-budgetary-projections-eu-member-states-2016-2070_en

AWG (2018b), Ageing Working Group. Italy country fiche on pension projections 2018. https://ec.europa.eu/info/publications/economy-finance/2018-ageing-report-economicand-budgetary-projections-eu-member-states-2016-2070_en

Belloni, M. and C. Maccheroni (2013). Actuarial Fairness When Longevity Increases: An Evaluation of the Italian Pension System, The Geneva Papers on Risk and Insurance: Issues and Practice. 38(4): 638-674.

Benítez-Silva, H., R. Disney, and S. Jiménez-Martín. (2010). Disability, Capacity for Work, and the Business Cycle: An International Perspective. Economic Policy. 25(63): 483-536.

Billig, A. and J.C. Ménard. (2013). Actuarial balance sheets as a tool to assess the sustainability of social security pension systems. International Social Security Review, 66(2): 31-62.

Billig, A.; and J-C Ménard (2018). Measuring and reporting the actuarial obligations of the Canada Pension Plan. International Social Security Review, 71(3): 49-71.

Billig, A.; S. Brimblecombe and J-C Ménard (2018). Introduction: Quantifying and reporting social security obligations. International Social Security Review, 71(3): 5-11. 
Blomberg, R. (2013), "Who Is Granted Disability Benefit in Sweden? Description of Risk Factors and the Effect of the 2008 Law Reform.” Master's thesis in Mathematical Statistics, Royal Institute of Technology, School of Engineering Sciences, Stockholm, Sweden.

Boado-Penas, M.C. and C. Vidal-Meliá. (2013). "The Actuarial Balance of the Pay-AsYou-Go Pension System: The Swedish NDC model versus the US DB model." In Holzmann, R., Palmer, E. and D. Robalino, eds., NDC Pension Schemes in a Changing Pension World, Chapter 14, Volume 2. Washington, DC: World Bank.

Boado-Penas, M.C. and C. Vidal-Meliá. (2014). Nonfinancial defined contribution pension schemes: is a survivor dividend necessary to make the system balanced? Applied Economics Letters, 21(4): 242-247.

Boado-Penas, M.C., Valdés-Prieto, S. and C. Vidal-Meliá. (2008). An Actuarial Balance Sheet for Pay-As-You-Go Finance: Solvency Indicators for Spain and Sweden, Fiscal Studies, 29(1): 89-134.

Board of Trustees, Federal Old-Age and Survivors Insurance and Disability Insurance Trust Funds (BOT). (2018). 20187 Annual Report. Washington, D.C.: Government Printing.

Borghans, L., A. C. Gielen, and E. F.P. Luttmer. (2014). Social Support Substitution and the Earnings Rebound: Evidence from a Regression Discontinuity in Disability Insurance Reform. American Economic Journal: Economic Policy, 6(4):1-39.

Buchholtz, S., A Chłon-Dominczak, and M. Góra. (2019). The Polish NDC Scheme: Success in the Face of Adversity. (SOCIAL PROTECTION \& JOBS Discussion Paper; 1902). The World Bank.

Canadian Institute of Actuaries (CIA). (2017). "Social security programs”, in Standards of Practice. Ottawa, Canadian Institute of Actuaries.

Cavanagh, J., S. Flynn and D. Moretti. (2016), Implementing Accrual Accounting in the Public Sector. Fiscal Affairs Department, IMF, Technical notes and manuals.

Chen, G. and D.S. Matkin. (2017). Actuarial inputs and the valuation of public pension liabilities and contribution requirements: a simulation approach. Public Budgeting and Finance, 37(1): 68-87.

Chłoń-Domińczak, A. and P. Strzelecki (2013), The minimum pension as an instrument of poverty protection in the defined contribution pension system - an example of Poland, Journal of Pension Economics and Finance, 12(30): 326-350.

CRS (2018). Trends in Social Security Disability Insurance Enrollment. Congressional Research Service. https://crsreports.congress.gov

D’Ambrogi-Ola, B.; and R. L. Brown. (2018). Measuring and reporting obligations of social security retirement systems: Actuarial perspectives. International Social Security Review, 71(3): 13-25.

Dabbicco, G. (2015). The Impact of Accrual-Based Public Accounting Harmonization on EU Macroeconomic Surveillance and Governments' Policy Decision-Making. International Journal of Public Administration, 38 (4): 253-267

De Haan, J., Janssen, K., \& Ponds, E. H. M. (2012). The Holistic Balance Sheet as the New Framework for European Pension Supervision - Evaluation from a Dutch Perspective. (Netspar Discussion Paper; Vol. 10/2012-033). Tilburg: NETSPAR. 
De Vries, G. (2010). Pension accounting standards. ECB/Eurostat e-book of the Workshop on Pensions, 55-78.

Drouin, A., P. Plamondon and C. Lloret (2018). Towards a fair assessment of social security liabilities under pay-as-you-go and partially funded schemes. International Social Security Review, 71(3): 81-103.

Duran, X., Vanroelend, C., Deboosere, P., \& Benavides, F.G. (2016). Social security status and mortality in Belgian and Spanish male workers. Gaceta Sanitaria, 30(4): 293295.

EC (2018). The 2018 ageing report: Economic and budgetary projections for the $28 \mathrm{EU}$ Member States (2016-2070) (European economy institutional paper, No. 079). Luxembourg, Publications Office of the European Union.

EC et al. (2009). System of national accounts 2008. Brussels, European Commission, International Monetary Fund, Organisation for Economic Co-operation and Development, United Nations, World Bank.

Edwards, G., Martinez, G. and Contreras, J.P. (2015). “An Empirical Analysis of Possible Reforms to the Disability and Survivors Insurance in Chile." Journal of Population Ageing, 8(4): 279-302.

Eurostat (2010). European system of accounts ESA 2010. Luxembourg.

Eurostat. (2011). Technical compilation guide for pension data in national accounts (Eurostat methodologies and working papers). Luxembourg, Eurostat, European Central Bank.

Foote, A., M. Grosz, and S. Rennane. (2019). The Effect of Lower Transaction Costs on SSDI Application Rates and Participation. Journal of Policy Analysis and Management, 38: $99-123$

Fredriksen, D. and Stølen, N.M. (2015), "Life Time Pension Benefits Relative to Life Time Contributions”, Discussion Paper No 825, Statistics Norway

Fredriksen, D., Holmøy, E., Strøm, B., \& Stølen, N. (2019). Fiscal effects of the Norwegian pension reform - A micro-macro assessment. Journal of Pension Economics and Finance, 18(1): 88-123.

García-Gómez P., Gielen A.C. (2018). Mortality effects of containing moral hazard: Evidence from disability insurance reform. Health Economics. 27(3): 606-621.

Gjesdal, S., Svedberg, P., Hagberg, J., \& Alexanderson, K. (2009). Mortality among disability pensioners in Norway and Sweden 1990-96: Comparative prospective cohort study. Scandinavian Journal of Public Health, 37(2): 168-175.

Golosov, M., and Tsyvinski, A., (2016). Designing Optimal Disability Insurance: A Case for Asset Testing. Journal of Political Economy. 114 (2): 257- 79.

Halvorsen, E. and Pedersen, A.W. (2019), Closing the gender gap in pensions: A microsimulation analysis of the Norwegian NDC pension system, Journal of European Social Policy, 29(1): 130- 143.

Holzmann, R., Palacios, R. and A. Zviniene. (2001). On the economics and scope of implicit pension debt: an international perspective. Empirica, 28(1): 97-129. 
IAA. (2013). International standard of actuarial practice 2: Financial analysis of social security programs (ISAP 2). Ottawa, International Actuarial Association.

IAA. (2018). Measuring and reporting actuarial obligations of social systems. Ottawa, International Actuarial Association - Social Security Committee

IMF. (2014). Government finance statistics manual 2014. Washington, DC, International Monetary Fund.

IPSASB. (2017a). “IPSAS 1: Presentation of Financial Statements”, in Handbook of international public sector accounting pronouncements 2017: Vol. 1. New York, NY, International Federation of Accountants - International Public Sector Accounting Standards Board.

IPSASB. (2017b). "Recommended Practice Guideline 1: Reporting on the long-term sustainability of an entity's finances", in Handbook of international public sector accounting pronouncements 2017: Vol. 2. New York, NY, International Federation of Accountants - International Public Sector Accounting Standards Board.

IPSASB. (2017c). “The Conceptual Framework for General Purpose Financial Reporting by Public Sector Entities", in Handbook of international public sector accounting pronouncements 2017: Vol. 1. New York, NY, International Federation of Accountants - International Public Sector Accounting Standards Board.

IPSASB. (2019). Proposed International Public Sector Accounting Standard $₫$ : Social Benefits (IPSAS-42). New York, NY, International Federation of Accountants International Public Sector Accounting Standards Board.

ISSA (2018), Social Security Programs Throughout the World. Social Security Administration (SSA) and the International Social Security Association (ISSA). http://www.socialsecurity.gov/policy

ISSA; ILO. (2016). ISSA-ILO Guidelines on actuarial work for social security. Geneva.

Jabłonowski, J. and C. Freudenberg (born Müller) (2014), A long-term assessment of the Polish disability fund and its possible reform. https://www.researchgate.net/publication/329754032_A_LONG-

TERM_ASSESSMENT_OF_THE_POLISH_DISABILITY_FUND_AND_ITS_POSSI BLE_REFORM

Jönsson, L., Palme, M. and Svensson, I. (2012), 'Disability insurance, population health and employment in Sweden', in Wise, D. A. (ed.), Social Security Programs and Retirement around the World: Historical Trends in Mortality and Health, Employment, and Disability Insurance Participation and Reforms, Chicago: University of Chicago Press.

Kaier, K. and C. Müller. (2015). New figures on unfunded public pensions entitlements across Europe: Concept, results and applications. Empirica, 42(4): 865-895

Knell, M. (2018). Increasing life expectancy and NDC pension systems. Journal of Pension Economics and Finance, 17(2): 170-199.

Lassila, J.; Valkonen, T. (2008), Applying The Swedish Pension Brake. Helsinki: ETLA, Elinkeinoelämän Tutkimuslaitos, The Research Institute of the Finnish Economy, No. 1127). 
Li. Y. (2018). Paradoxical effects of increasing the normal retirement age: a prospective evaluation. European Economic Review, 101, 512-527.

Lindner, S. (2016). How do unemployment insurance benefits affect the decision to apply for social security disability insurance? Journal of Human Resources, 51, 62-94.

Low, H., and Pistaferri, L., (2015). Disability Insurance and the Dynamics of the Incentive-Insurance Tradeoff. American Economic Review. 105, 2986- 3029.

Mason, P. (2018). Accounting for social benefits: The search for a past event. International Social Security Review, 71(3): 73-80.

Melis, R. and Trudda A. (2012). Financial and demographic risks impact on a pay-asyou-go pension fund. Economics Bulletin, 32(2): 1320-1329.

Metzger, C. (2018). An actuarial balance sheet of the Swiss old-age pension scheme. International Social Security Review, 71(1): 25-49.

Metzger, C. (2019). The German statutory pension scheme: Balance Sheet, Crosssectional Internal Rates of Return and Implicit Tax Rates. Fiscal Studies. In press.

Michaud, A., Nelson, J., Wiczer, D., (2018). Vocational Considerations and Trends in Social Security Disability, The Journal of the Economics of Ageing, 11, 41-51.

OECD (2018), OECD Reviews of Pension Systems: Latvia, OECD Publishing, Paris. http://dx.doi.org/10.1787/9789264289390-en

OECD (2019), Public spending on incapacity (indicator). doi: 10.1787/f35b71ed-en (Accessed on 20 May 2019).

OSFIC. (2015). Canada Pension Plan Retirement, Survivor and Disability Beneficiaries Mortality Study (Actuarial study, No. 16). Ottawa, Office of the Superintendent of Financial Institutions - Office of the Chief Actuary.

OSFIC. (2018). Measuring and reporting actuarial obligations of the Canada Pension Plan (Actuarial study, No. 19). Ottawa, Office of the Superintendent of Financial Institutions - Office of the Chief Actuary.

Palmer, E. and B. Könberg (2019). The Swedish NDC Scheme: Success on Track with Room for Reflection. (SOCIAL PROTECTION \& JOBS Discussion Paper; 1901). The World Bank.

Park, J-M., Ukchan, O., Beop-Rae, R. \& Yeongmin, M., (2017). Disparities in mortality by disability: an 11-year follow-up study of 1 million individuals. International Journal of Public Health, 62, 969-996.

Pérez-Salamero González, J.M., Ventura-Marco, M. and C. Vidal-Meliá. (2017). A 'Swedish' Actuarial Balance Sheet for a Notional Defined Contribution Pension Scheme with Disability and Minimum Pension Benefits. International Social Security Review, 70 (3): 79-104.

Phaup, M. (2019). Budgeting for Mandatory Spending: Prologue to Reform. Public Budgeting and Finance, 39(1): 24-44.

Pitacco, E. (2014). Health Insurance. Basic Actuarial Models. EAA Series. Heidelberg.

Plamondon, P., A. Drounin, G. Binet, M. Cichon, W. McGillivray, M. Bédard, and H. Pérez-Montas. (2002). Actuarial Practice in Social Security. Quantitative Methods in 
Social Protection Series. Geneva: International Social Security Association and International Labour Office.

Qi, h., J. Helgertz, T. Bengtsson (2018). Do notional defined contribution schemes prolong working life? Evidence from the 1994 Swedish pension reform. The Journal of the Economics of Ageing, 12, 250-267.

Rashbrooke, G. (2008). Exploration of application of actuarial Accounting methodology to the New Zealand flat rate social security pension. Presented at a joint Colloquium of the IACA, PBSS and IAAHS Sections, Boston, U.S.A. 4-7 May 2008.

Regúlez-Castillo, M. and C. Vidal-Meliá (2012). Individual information for pension contributors: Recommendations for Spain based on international experience, International Social Security Review, 65(2): 1-27.

Settergren, O. (2013). "A Decade of Actuarial Accounting for the NDC Scheme in Sweden: Quantifying Change in the Financial Position of a PAYG Pension Plan”. In Holzmann, R., Palmer, E. and D. Robalino, eds. NDC Pension Schemes in a Changing Pension World, Chapter 21, Volume 2. Washington, DC: World Bank

Settergren, O. and B.D. Mikula. (2005). The rate of return of pay-as-you-go pension systems: a more exact consumption-loan model of interest. Journal of Pensions Economics and Finance, 4(2): 115-138.

Society of Actuaries (SOA). 2014. RP-2014 Mortality Table Report Released in October 2014.

Stavrakis, C. (2018). Reporting the pension obligations of social security schemes: An EU perspective. International Social Security Review, 71(3): 105-123.

Sundén, A. (2012). "The challenge of reaching participants with the message of NDC", in R. Holzmann, E. Palmer and D. Robalino (eds), Nonfinancial defined contribution pension schemes in a changing pension world: Vol. 2: Gender, politics, and financial stability. Washington, DC, World Bank. pp. 257-272 (Chapter 17).

Takayama, N. (2005). Social Security Pensions in Japan: A Balance Sheet Approach. The Economic and Labour Relations Review, 15(2): 263-283.

The Swedish Pension System. Orange Annual Report 2001. (TSPS) (2002). Ed. Ole Settergren. The National Social Insurance Board (Riksförsäkringsverket, RFV), Stockholm.

The Swedish Pension System. Orange Annual Report 2017. (TSPS) (2018). Ed. Ole Settergren. Swedish Pensions Agency (Pensionsmyndigheten), Stockholm.

Venti, S., Wise, D. A. (2015). The long reach of education: Early retirement. The Journal of the Economics of Ageing, 6, 133-148.

Ventura-Marco, M. and C. Vidal-Meliá. (2014). An Actuarial Balance Sheet Model for Defined Benefit Pay-As-You-Go Pension Systems with Disability and Retirement Contingencies. Astin Bulletin, 44(2): 367-415.

Ventura-Marco, M. and C. Vidal-Meliá. (2016). Integrating retirement and permanent disability in NDC pension schemes. Applied Economics, 48(12): 1081-1102.

Vidal-Meliá, C. (2014). An assessment of the 2011 Spanish pension reform using the Swedish system as a benchmark. Journal of Pension Economics and Finance. 13(3): 297333. 
Vidal-Meliá, C. and M.C. Boado-Penas. (2013). Compiling the actuarial balance for payas-you-go pension systems. Is it better to use the hidden asset or the contribution asset? Applied Economics, 45(10): 1303-1320.

Vidal-Meliá, C., Boado-Penas, M.C. and F. Navarro-Cabo. (2016). Notional defined contribution pension schemes: why does only Sweden distribute the survivor dividend? Journal of Economic Policy Reform, 19(3): 200-220.

Vidal-Meliá, C., Boado-Penas, M.C. and O. Settergren (2010). Instruments for improving the equity, transparency and solvency of PAYG pension systems. NDCs, ABs and ABMs. In Micocci, M., Gregoriou, G.N. and G. B. Masala (Eds.), Pension fund risk management, pp.419-473, Financial and actuarial modelling, New York: Chapman and Hall. chapter 18, ISBN 1439817520.

Vidal-Meliá, C., Boado-Penas, M.C. and O. Settergren. (2009). Automatic balance mechanisms in pay-as-you-go pension systems. Geneva Papers on Risk and Insurance Issues and Practice, 34(2): 287-317.

Vidal-Meliá, C., Ventura-Marco, M. and Pérez-Salamero González, J.M. (2018). “Social insurance accounting for a notional defined contribution scheme combining retirement and long-term care benefits.” Sustainability, 10, 2832

Wiener, M.; Stokoe, P. (2018). Discussing accrued-to-date liabilities. International Social Security Review, 71(3): 27-48.

Wiese, P. (2006), "Financing Disability Benefits in a System of Individual Accounts: Lessons from International Experience”, Center for Retirement Research at Boston College, WP 2006-4.

Willis, R. (1988). Life cycles, institutions and population growth: A theory of the equilibrium interest rate in an overlapping-generations model. pp. 106-138 in R.D. Lee, W.B. Arthur, \& G. Rodgers, eds., Economics of Changing Age Distributions in Developed Countries. Oxford: Clarendon Press

ZUS (2017), Social Security in Poland, ZUS, Warsaw. 


\section{APPENDIX 1.- GLOSSARY}

Accrual (or comprehensive) accounting principle: This principle recognizes transactions or events when they occur, irrespective of when the cash is paid or received. It seeks to match the costs incurred during a particular accounting period with the benefits earned, and the revenues with the goods or services provided.

Accrued-to-date pension liability (ADL): In conceptual terms, this is similar to a termination reserve in a private sector or occupational pension plan. The level of the termination reserve can be regarded as the full funding level of the scheme. This amount thus also equals the resources that would be required to shut down a SSS while honouring all past commitments (Holzmann et al., 2001; Kaier and Müller, 2015; Drouin et al., 2018).

Advance funding financing method: Fully funded schemes use the full advance funding method, in which contributions are established to match the full cost of future benefits as these costs are incurred through current service. Such financing methods also provide for amortization over a fixed period for any financial obligation that is incurred at the beginning of the program (or subsequent modification) as a result of granting credit for past service (BOT, 2018).

Asset test: A form of means test in which a person receives the supplementary benefit only if his/her assets are below a legislated threshold (Golosov and Tsyvinski, 2016).

Automatic balance mechanism (ABM): An ABM is a set of predetermined measures established by law to be applied immediately as required according to an indicator that reflects the system's financial health. Its purpose, through successive application, is to provide what could be called automatic financial stability, which can be defined as the capacity of a pension system to adapt to financial turbulence without legislative intervention. Turbulence can be caused by economic or demographic shocks that have an effect on the system's solvency or financial equilibrium (Vidal-Meliá et al., 2008).

Balance ratio: The contribution asset and the buffer fund, divided by the pension liability of the system.

Balance sheet: A statement, drawn up on a particular date, in relation to a specific entity of the values of assets owned and controlled and of the liabilities owed by an institutional unit or group of units (Eurostat, 2010).

Canadian actuarial valuation report (CAVR): In Canada, similar methodology to that applied in the US has been used to draw up an AVR on the Canadian Pension Plan (CPP) every three years since 1966. This involves projecting revenue and expenditure over a period of 75 years with the aim of accurately assessing the future effects of historical and projected trends in demography and economic factors. The CPP is considered unsustainable if the projected steady-state contribution rate (SSCR) for the next 75 years needs to be greater than that established by law (currently 9.9 percent) OSFIC (2018). The SSCR is the key financial measure for evaluating the CPP, specifically in relation to its adequacy and stability over time. It is defined as the lowest rate sufficient to ensure both the stabilization of the ratio of assets to the following year's expenditures over time and the long-term financial sustainability of the Plan without recourse to further rate increases. Specifically, CPP regulations require the steady-state contribution rate be the 
lowest rate such that the ratios of assets to the following year's expenditures (A/E ratios) in the $10^{\text {th }}$ and $60^{\text {th }}$ year following the third year of the most recent review period are the same (Billig and Menard, 2018; Billig et al., 2018). The most recent report corresponds to the 2016-2090 period.

Cash accounting principle: This principle recognizes transactions when cash is paid or received, but doesn't necessarily coincide with the timing of the services provided or benefits received.

Contingent asset: A possible asset that arises from past events, and whose existence will be confirmed only by the occurrence or non-occurrence of one or more uncertain future events not wholly within the control of the entity (IAS 37 - Provisions, Contingent Liabilities and Contingent Assets).

Contingent liability: A possible obligation depending on whether some uncertain future events occur, or a present obligation but payment is not probable or the amount cannot be measured reliably (IAS 37 — Provisions, Contingent Liabilities and Contingent Assets).

Defined benefit scheme/formula (DB): In a DB pension scheme the level of pension benefits promised to contributors is determined by a formula agreed in advance, either alone or in combination with a guaranteed minimum amount payable. The risk of a DB scheme to provide an adequate income in retirement or when the affiliate becomes disabled is borne by the sponsor.

Disabled: There are many definitions. It depends on the country. A person is considered disabled if he or she is determined to be suffering from a severe and prolonged mental or physical disability. A disability is considered severe if by reason of it the person is regularly incapable of pursuing any substantially gainful occupation; a disability is considered prolonged if it is likely to be long-term and of indefinite duration or is likely to result in death. (OSFIC, 2015).

Funded defined contribution (FDC) schemes: These schemes used to be termed as "money purchase pension schemes" Under these schemes each individual receives a retirement benefit that comes entirely from the capital accumulated in her/his individual account. The amount of the pension depends, essentially, on the following factors: The wage profile across the working life cycle of the individual, the rate of contribution, as percent of wages, to the individual accounts, the real and forecasted mortality rates at the retirement age, and the rate of interest (market return), both during the working life of the individual and at the moment of retirement (assuming that pensioners receive a fixed annuity computed at retirement). (Eurostat, 2010).

Income statement: It is also called a profit and loss statement, or a "P\&L". An income statement presents the results of a company's operations for a given period (In our context the pension scheme). The income statement presents a summary of the revenues, gains, expenses, losses, and net income or net loss of an entity for the period. Along with the balance sheet and the statement of cash flows, the income statement is one of the primary sources of financial information.

Japanese actuarial method (JAM): It is based on OG methodology and uses a 95-year valuation period. Given that financial resources available for funding benefits are fixed (contribution levels and national subsidies), the method predicts, for several scenarios, the adjusted benefit levels in order to keep pension finances in equilibrium. Under the 
current actuarial method, the period of financial equilibrium is finite, whereas the former method, applied until 1999, considered a perpetual time horizon. The latter time horizon was ruled out mainly because if the share of elderly population became very high, as was the case in Japan, the public pension system would have to manage enormous financial assets to be able to make use of the investment profit in the future. JAM must be carried out at least every five years. The most recent report corresponds to 2014-2110 period (AAD, 2017).

Mandatory spending: The defining characteristics of mandatory spending are that existing legislation has provided authority to obligate funds without future legislative action, and that beneficiaries have a political claim to "earned" benefits, even though they do not have a legally enforceable claim, if the authorizing law is changed (Phaup, 2019).

Multiple overlapping generations model (MOLG): In our context, this model can be defined as a multi-state non-homogeneous Markov process in which inhomogeneity is already given because we work with participants of different ages in the context of overlapping generations and also with different patterns of transitions between states for a given range of ages. The model brings an actuarial approach to the accounting framework for organizing, summarizing and interpreting data on transfer systems and the life cycle developed in Lee (1994), Willis (1988) and Arthur \& McNicoll (1978).

Notional defined contribution (NDC) scheme: A PAYG pension plan that mimics a funded defined contribution plan. In this scheme, contributions (both from employee and from employer) are credited to, and accumulated on, individual accounts. Those individual accounts are notional, in the sense that the contributions to the schemes are used to pay pension benefits to current pensioners. At retirement, the accumulated balance is converted into an annuity through a formula, based, among other factors, on a measure of life expectancy, and is revised annually to catch up with a measure of the standard of living (Eurostat, 2010). Another relevant feature is that this scheme, if well designed, is fair in a sense that two individuals from the same birth cohort who make the same contributions into the scheme in the same period can expect to receive the same pension.

These schemes are designed to balance liabilities and assets thus providing stability, and provides account information to participants as well as a system-wide financial statement; and changes the rhetoric of pension systems; it makes people think in terms of accounts (savings) rather than entitlements.

Pay-as-you-go method: A financing method in which contributions are established to produce just as much income as required to pay current benefits; i.e., current contributors allow the use of their contributions or taxes to pay current pensioners' benefits (previous contributing generations) (BOT, 2018).

Pension reclassification: When a disabled pensioner reaches statutory retirement age, his or her disability benefits are (re)classified as retirement benefits. This is a widespread practice that masks the system's real status unless further pension information becomes available (Ventura-Marco and Vidal-Meliá, 2014).

Populism in pensions: The use of the public system as an electoral weapon by politicians, higher spending in the pension system is generated by unjustified increases in minimum pensions, the increase or extension of payments without the contributions to cover them, the awarding of disability pensions without rigour and contribution subsidies. Once the 
elections are over, the populist politician presumably obtains his more or less ephemeral reward, but the cost to the pension system becomes structural.

Social security pension schemes (SSSs): Contractual insurance plans where the affiliates as participants are obliged by general government to insure against old age and other risks such as disability, health etc. (Eurostat, 2010).

Supplementary table (Table 29): The aim of the supplementary table is to give an overview of pension obligations (of general government but also of other institutional sectors) vis-à-vis households covering all pension schemes in social insurance. The figures in Table 29 present the perspective of the debtor (the pension scheme) indicating pension obligations (either liabilities or contingent liabilities) as well as that of the creditor (households) showing pension entitlements (either assets or contingent assets) (Eurostat, 2011).

Sustainability: This term has to be understood as the system's ability to fulfil current promises to pay benefits to beneficiaries in the long term without recurring to further increases in contribution rates, and/or that the sponsor will be forced to allocate extraordinary funds to cover the financing gap.

The Ageing Working Group (AWG) pension reporting: The AWG is a wellestablished EU framework, which has been in force since 2001. The most updated AWG pension exercise covers the period 2016-2070 (EC, 2018). The long-term projections show where (in which countries), when, and to what extent ageing pressures will accelerate as the baby-boom generation retires and as the people in the EU are expected to live longer in the future. Hence, the projections are helpful in highlighting the immediate and future policy challenges for governments posed by projected demographic trends.

True and fair view (TFV): TFV ensures that financial statements reflect the economic realities of a business and its financial transactions. It is the comer stone in financial reporting. Auditors include an opinion in the audit report as to whether the financial statements of the audited company show a TFV. This opinion is important to users when taking decisions about the company because it is the opinion of someone independent of the company who has analyzed the company's financial statements. If the opinion is that, the information shows a TFV, then users know that the company has complied with the applicable accounting standards or in the case where an accounting standard was not adequate, then additional information was included or that the standard in question was overridden in order to show a TFV.

US actuarial balance (US AB): The US AB is a measure of the programme's financial status for its 75-year valuation period as a whole. It is calculated for a traditional scenariobased model and also using a stochastic model. It includes the trust fund asset reserves at the beginning of the period, all costs and income during the valuation period, and the cost of reaching a target trust fund reserve of one year's cost by the end of the period. AB is expressed as a percentage of the taxable payroll for the 75-year valuation period. This single number summarizes the adequacy of programme financing for the period. The US $\mathrm{AB}$ is also calculated over the infinite horizon, but results are subject to much greater uncertainty (BOT, 2018). The US AB is compiled yearly since 1941. 


\section{APPENDIX 2.-DISABILITY, MINIMUM (GUARANTEED) PENSION BENEFITS AND NDCS IN PRACTICE.}

This appendix gives a brief picture on how disability benefits are treated within the NDC framework and its relation with minimum pension benefits. NDC plans are generally incorporated as one of the pillars in multi-pillar schemes that also include pillars based on other models, such as a mandatory funded DC and/or a social pension pillar. Latvia was the first country to fully implement a NDC scheme whereas such schemes were implemented gradually in Italy, Sweden and Poland in the 1990s and in Norway in 2011.

Although a NDC scheme provides benefit for everyone who works and contributes to it, it will not necessarily provide everyone with a benefit that gives sufficient income for them to live on. It has long been recognized that NDC schemes should be supplemented with a minimum pension benefit (MPB). The introduction of a MPB is a way of preserving the social sustainability of the scheme as well as the adequacy of the pension.

In the NDC schemes currently in place, retirement and permanent disability are not well integrated; many inconsistencies can be observed. Italy is the unique country in which the rate of contribution is not separated into contingencies, and the formula for calculating the disability benefits is embedded into the general formula for determining the retirement benefits. Also, the survivor benefits are included in the same formula.

In Sweden, the current regulations on disability pensions are linked to the retirement pension system but not integrated into it. Individuals with disability benefits continue to accumulate pension entitlements in the public pension system. The pension contributions are paid from the central government's budget. These payments, which are made annually from general tax revenues, are entered in the country's accounts as a cost for the disability system and are part of the transfer from state revenues to the NDC pension fund. The formula for calculating benefits remains DB. Benefits are calculated as 64 percent of the assumed income; that is, the highest income from three of the last five-to-eight years, depending on age, up to a social security ceiling (Jönsson et al, 2012).

Permanent disability benefits are converted into retirement benefits at the age of 65 (66 in 2023). Because disability benefits are determined by a defined benefit formula, while old age benefits are determined by individual accounts, discontinuities in benefit levels are likely to occur when an individual switches from disability benefits to old age benefits (Wiese, 2006).

The profound changes introduced to the public old-age pension system in Poland in 1999, 2011, 2012 and 2014 left the disability benefit scheme unchanged ${ }^{16}$ (Chłoń-Domińczak and Strzelecki, 2013; AWG, 2018a; Buchholtz et al., 2019).

\footnotetext{
${ }^{16}$ It is not easy to give a brief description of the Polish Pension system regarding the retirement contingency. Currently, under the general pension system there are several groups of insured individuals classified according to different sections of the system:

a) People born before 1949 remained in the old DB system.

b) People born 1949-1968 had a right to choose if they wanted to join a funded pillar or stay in a one pillar NDC. Their pension rights were recalculated into the new system as initial capital. If they chose a one pillar system they have a one NDC account (They "earn” interest on accumulated contributions equal to the change in the overall contribution revenue, which represents the changes in the covered wage bill growth.)

c) People born 1949-1968 who didn't choose the one pillar system and who joined the funded tier and people born after 1968 who were obliged to join the funded pillar have the following situation: Their pension rights were recalculated into the new system as initial capital. They have two NDC accounts (account and subaccount).
} 
In 2010 it was proposed by the government to replace the old formula for calculating disability benefits which was based on the length of the contributory and non-contributory periods, with a new one linking disability pensions to the amount of the old-age NDC pension entitlements. The reform had the objective of providing a consistent calculation of disability and retirement pensions. To avoid the situation of when young affiliates who become disabled and have an insufficient contributory record (less than 30 years) resulting in a low value in the NDC account were exposed to poverty, it was planned to add a "contributory bonus". To calculate the disability benefit, the accumulated notional capital was going to be increased by the average monthly contribution for each month that was missing to fulfil the 30 years from the year of application for disability benefit and the year of the persons $60^{\text {th }}$ birthday. The monthly disability benefit would be equal to the ratio of the pension balance (estimated notional capital) and the expected unisex life expectancy at 60 years old. Due to presumed negative effects on replacement rates, the reform was rejected.

The disability pensions of persons who have reached the statutory retirement age ${ }^{17}$ is replaced with old-age pensions. The rules of the system currently in operation make it possible that most disability beneficiaries who reach the statutory retirement age may expect higher retirement benefits than individuals retiring under the NDC/FDC system in force. The disability benefit formula in place is quite a complex procedure, based on the length of the contributory and non-contributory periods, the general base amount (BA), a common amount used countrywide for all types of social benefits, the hypothetical carrier path and the degree of disability (person completely unable to work or partly unable to work). (Jabłonowski and Freudenberg, 2014; ZUS, 2017; AWG, 2018a).

In Italy, the formula used to calculate the disability pension does not provide a clear link between benefits and contributions (AWG, 2018b). Under the NDC scheme, the retirement benefit is calculated as a product of two factors: the total lifelong contributions, capitalized with the nominal GDP growth rate (five-year geometric moving average) and the transformation coefficient, the calculation of which is mainly based on the probabilities of death, the probabilities of leaving a surviving spouse, and the average outliving period.

The retirement benefit (adapted to the nomenclature used in our model) for an individual who retires at the ordinary retirement age $\left(x_{e}+A=r\right)$ at time $t$ after contributing for the maximum number of years $(c=A)$, is computed as:

$$
P_{(r, c, t)}^{R}=K_{(r, c, t)}^{a c} \cdot T_{(r)}^{t}=\frac{\overbrace{\theta_{a} \cdot \sum_{s=0}^{A-1} y_{\left(x_{e}+s\right)} \cdot \prod_{h=s}^{A-1}(1+\overline{G d p})}^{\text {accumulated notional capital }}}{\underbrace{\delta_{(r)}^{t}}_{\text {annuity divisor }}}
$$

FDC account active - if they decided to stay in a funded pillar after the 2013 reform and still pay contributions to this pillar.

FDC account non-active - if they decided to pay all contributions to NDC accounts but part of the funds remained accumulated in the funded system.

In the NDC subaccount the contributor earns an interest rate based on quarterly GDP growth, and similarly to the Swedish NDC account, the capital accumulated is inherited if the worker dies before reaching retirement age.

d) People who entered the labour market after the 2013 reform and didn't choose the funded pillar. They have two NDC accounts (account and subaccount).

17 The statutory retirement age for men and women is being risen gradually, for women from 60 to 67 (from 2013 until 2040) and for men from 65 to 67 (from 2013 until 2020). 
Where, $K_{(r, c, t)}^{a c}$, is the accumulated notional capital for an individual who retires at the ordinary retirement age at time $t$ after contributing for the maximum number of years;

$T_{(r)}^{t}=\frac{1}{\delta_{(r)}^{t}}$ is the conversion coefficient ${ }^{18}$;

$\delta_{(r)}^{t}$ is the annuity divisor to transform the accumulated entitlements (pension wealth, notional capital) into the annual pension benefit;

$\theta_{a}$ is the accredited contribution rate;

$y_{\left(x_{e}+s\right)}$ is the contribution base for the contributor aged $x+s$;

$\overline{G d p}_{h}$ is the geometric mean of the nominal GDP growth rate in the 5 years preceding the year in which the attained age of the contributor is $x_{e}+s$.

Unlike the Swedish model and the Polish NDC subaccount, the capital accumulated in the individual pension balance does not include inheritance gains; i.e., the account balances of affiliates who do not survive until retirement, are distributed as a survivor dividend to the accounts of the non-disabled active survivors on a birth cohort basis.

Except for the issue of the survivor dividend, Formula (7) presents the typical structure of those used in NDC schemes, but in reality, it is very specific due to the fact that the annuity divisor includes the possibility of paying survivor benefits:

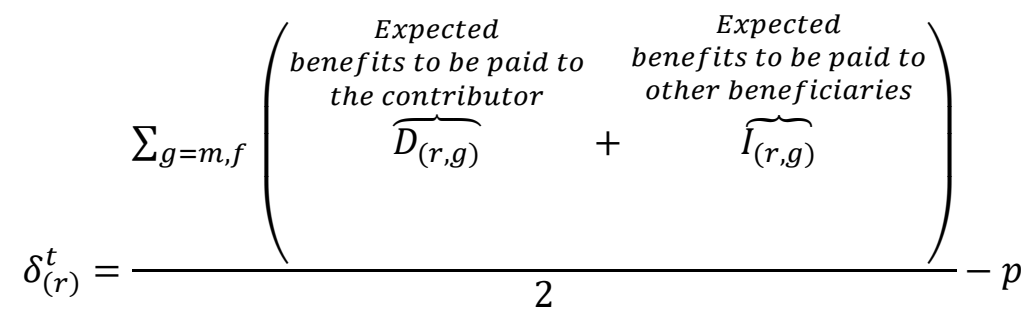

$$
\begin{aligned}
& D_{(r, g)}=\sum_{k=0}^{w-r-1}{ }_{k} P_{(r, g)} \cdot\left(1+G d p_{f}\right)^{-k}=\sum_{k=0}^{w-r-1}{ }_{k} P_{(r, g)} \cdot\left(\frac{1+\lambda}{1+r}\right)^{k} \\
& I_{(r, g)}=\gamma_{s} \cdot \sum_{k=0}^{w-r-1}{ }_{k} P_{(r, g)} \cdot q_{(r+k, g)} \cdot\left(1+G d p_{f}\right)^{-k} \cdot \vartheta_{(r+k, g)} \cdot a_{(r+k+1, g *)}^{w i} \\
& a_{(r+k+1, g *)}^{w i}=\sum_{l=1}^{w-r-k+\varepsilon_{g}}{ }_{l} P_{\left(r+k+1-\varepsilon_{g}, g *\right)} \cdot q_{\left(r+k+l-\varepsilon_{g}, g *\right)}^{r m} \cdot\left(1+G d p_{f}\right)^{-l} .
\end{aligned}
$$

Where,

$D_{(r, g)}$ is the present value at age $r$ of 1 monetary unit of a lifetime pension payable in advance with a real technical interest rate equal to $G d p_{f}$;

\footnotetext{
${ }^{18}$ Until the end of 2012, the transformation coefficients were foreseen only for the age bracket 57-65. For retirement ages below (i.e. disability pensions) or above the range, the lowest and the highest coefficients were respectively applied. As of 2013, the upper limit of the age range has been extended to 70 and then further, in line with the increase in the eligibility requirements brought about by changes in life expectancy (AWG, 2018b)
} 
$p$ is an actuarial adjustment factor that considers the way in which pensions are provided (1 month in advance, 2 months in advance, 1 year in advance and so on)

${ }_{k} P_{(r, g)}$, is the gender-s-specific probability that a person aged $r$ years will reach age $r+$ $k$;

$w$ is the maximum life span;

$\frac{(1+r)}{(1+\lambda)}-1=G d p_{f}$ is the long-run expected GDP real growth rate; $r$ is the internal rate of return in nominal terms; $\lambda$ is the pension in payment indexation rate.

$I_{(r, g)}$ is the present value at age $r$ of survivor benefits linked to 1 unit of retirement benefits;

$q_{(r+k, g)}$ is the gender-s-specific probability that a person aged $r+k$ years will die within the year;

$\gamma_{s}$ is the fraction of the annuity paid to the widow(er) $\left(\gamma_{s}=0.6 \cdot \pi_{s}\right)$, where $\pi_{s}$ is a gender earning related reduction factor, set equal to (0.7) 0.9 if $g$ is (fe)male);

$\vartheta_{(r+k, g)}$ is the age-and-gender specific probability to be married;

$a_{(r+k+1, g *)}^{w i}$ is the present value of 1 monetary unit of a lifetime pension paid to the widow(er) at age $r+k+1$;

$\varepsilon_{g}$ is the age difference between pensioner and his/her widow(er);

$g *$ stands for the gender of the widow(er);

$q_{\left(r+k+l-\varepsilon_{g}, g *\right)}^{r m}$ is the age and gender-specific probability for the widow(er) to remarry.

The formula for calculating disability benefits (adapted to the nomenclature used in our model) is even more complex. For an individual who becomes disabled at age $\left(x_{e}+k=\right.$ $d$ ) at time $t$ after having contributed for the maximum possible number of years $(c=k)$, is computed as:

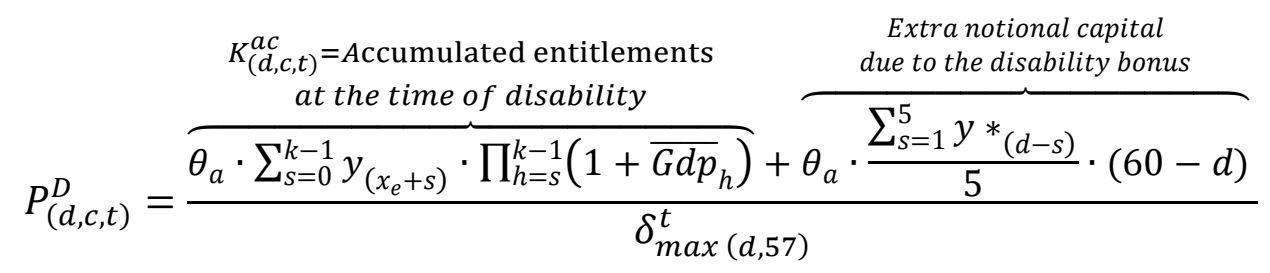

Where, $y *_{(d-s)}$, is the appropriately adjusted contribution base in the preceding 5 years before the disability occurs.

As depicted in formula (12), disability pensions are based on the notional capital at the time of disability, and this is integrated taking into account the gap between the individual's age when the pension is awarded and the reference age of 60. More specifically, the disability benefit is computed firstly by applying rules as established for the old-age/early retirement pension. To the benefit computed in this way, a "contributory bonus", equal to the years of contributions from the age of claiming to the age of 60 , is then added ${ }^{19}$. This bonus is calculated based on the wages in the preceding 5 years before the disability onset. If the claimant is younger than 57 , the favourable conversion coefficient for retirement at age 57 is applied (Belloni and Maccheroni, 2013).

In Latvia, as in Sweden, when claiming a disability pension, the social security budget pays old-age pension contributions to the NDC and FDC accounts, hence accruing oldage pension entitlements. These contributions are based on half the average wage that is subject to social security contributions. In 2016 this amount was slightly lower than the

\footnotetext{
${ }^{19} \mathrm{Up}$ to a maximum of 40 years.
} 
minimum wage. Therefore, the benefits provide limited work disincentives as the old-age pension entitlements increase faster when working even at minimum wage than when claiming disability pension.

Disability benefits are determined by a defined benefit formula, the amount of the benefits depends on the degree of disability, the contribution base of the preceding 5 years before the disability occurs (the highest earnings for 3 years in the previous 5 -year period) and the number of contributed years.

Upon reaching the retirement age ${ }^{20}$, disability pensions are converted into old age pensions according to NDC rules, but the old-age pension cannot be lower than the granted disability benefit. The converted disability pensions might generate higher old age pensions for some individuals than those retiring at the official retirement age. These features might create some financial incentives to apply for disability pensions (OECD, 2018)

In Norway, the NDC scheme was implemented in 2011. As part of the pension reform in 2011, the Government proposed a new disability scheme and a new model for calculating old-age pensions for individuals previously classified as disabled. The new disability scheme was introduced from 2015, and under current regulations, the disability benefit is calculated more as a short-term benefit with a replacement rate of 66 per cent and taxed as earnings (Fredriksen and Stølen, 2015). Permanent disability benefits are converted into retirement benefits at the age of 67 . The government decided that the reduction in yearly benefits caused by growing life expectancy for a newly disabled at the age of 67 should only be one half of the reduction implemented for former non-disabled retiring at this age. By introducing a weaker life expectancy adjustment for earlier disabled, the reform may strengthen the incentives to retire as a disability pensioner (Fredriksen et al., 2019).

As far as the provision of guaranteed pension benefits is concerned, there are big differences among the countries with NDC schemes in force.

In Sweden, the guaranteed pension provides basic social security for individuals with little or no income. Residents in Sweden are eligible for a guaranteed pension beginning at age 65 . This will be raised to 66 . To receive a full guaranteed pension, an individual must have resided in Sweden for 40 years after the age of 25, however residence in another EU/EEA country can also be credited towards a guaranteed pension. The Swedish guarantee begins with a floor, above which it tapers off as it is means tested against the public NDC and FDC pensions (Palmer and Könberg, 2019). The guaranteed pension is financed by the tax revenue from the central-government budget and is therefore not included in the income statement and balance sheet of the pension system (TSPS, 2018).

Guarantee disability benefit is granted to those who have had little or no income. The size of the benefit depends on age and how long the individual has lived in Sweden (Blomberg, 2013).

In Poland, there is a minimum pension guarantee (MPG) linked to the contributory system. If the retirement pension (a sum of NDC and FDC pension, see Appendix 1) is below the minimum level, the pension is topped-up by the MPG, which is financed by the state budget. The guarantee is subject to eligibility criteria, which are reaching the minimum retirement age and work experience of 20 years for women and 25 years for

\footnotetext{
20 The normal retirement age is 63 years and 3 months for both men and women in 2018 and it will reach 65 in 2025.
} 
men (this requirement for women will increase with a rise in the retirement age). The MPG is also in force for permanent disability benefits (ISSA, 2018),

In Latvia, there are three sources of income to help older people meet a minimum standard of living: basic pension, minimum pension, and universal, age-independent guaranteed minimum income (GMI). The basic pension is a tax financed benefit for those who are over the retirement age and who fulfil the 5-year residency condition, but have less than 15 years of contribution to earnings-related pensions. Before 2017, the age threshold for being entitled to the basic pension was the retirement age plus five years.

Minimum pensions are granted to people who fulfil the 15-year contribution condition for regular pensions, but whose entitlements are lower than the minimum pension threshold. The minimum pension increases with the contribution period, from 15 years to a maximum of 41 years of contribution. The age-independent GMI benefit, which is provided by the municipalities, might complement the income of poor retirees. The GMI is paid to the households whose income per capita is below the established GMI threshold. This benefit covers the difference between income from other sources and the GMI threshold (OECD, 2018).

In Italy, there is a safety net for the elderly on low income, regardless of contributions. The safety net consists of two kinds of social assistance benefits: the old age allowance and additionally the low-income pension supplement. Both are means-tested and subject to a minimum age requirement of 65 years and 7 months in 2016, increased by 1 year in 2018, and linked to changes in life expectancy. The guaranteed minimum pension is paid to social insurance or mixed program pensioners with a monthly pension lower than the living minimum income. For the disability contingency, the amount depends on age and the annual income of the pensioner. For 2018, the minimum monthly disability pension is $€ 507.42$ for a pensioner aged 60 or older with personal income less than €13,192.92 and household income less than €26,385.84. There is no minimum disability pension otherwise. There is no maximum disability pension. (ISSA, 2018).

In Norway, strong elements of redistribution are maintained with the new NDC system. A guaranteed pension of 2 basic pension units (BPU) for singles and 1.85 BPU per person for couples secures a minimum level of benefits for pensioners with low labour incomes. BPU is a measurement unit in the National Insurance Scheme corresponding to about 1/6 of the average annual wage level for a full-time employee. The guaranteed pension secures a comparatively high minimum benefit to individuals with low earnings-related entitlements - with a gross level for a single pensioner at about 36 percent of an average fulltime wage. The guaranteed pension is means-tested by 80 per cent against NDCpension rights, and even persons with small incomes will obtain a level of pension benefits somewhat higher than the minimum level (2 or 1.85 BPU depending on the civil status of the recipient) (Fredriksen and Stølen, 2015; Halvorsen and Pedersen, 2019).

Table 6 summarizes the main features of the countries described above. 
Table 6: Disability, minimum (guaranteed) pension benefits and NDCs in practice: Summary (part 1)

\begin{tabular}{|c|c|c|c|}
\hline Countries/concepts & Disability formula & Minimum Pension/Guarantee & $\begin{array}{l}\text { Disability Benefits (DB) } \\
\text { in the retirement period }\end{array}$ \\
\hline Sweden & $\begin{array}{l}\text { Formula for calculating benefits remains defined } \\
\text { benefit. Benefits are calculated as } 64 \text { percent of } \\
\text { the assumed income. Individuals with disability } \\
\text { benefits continue to accumulate pension } \\
\text { entitlements in the public pension system. The } \\
\text { pension contributions are paid from the central } \\
\text { government budget. }\end{array}$ & $\begin{array}{l}\text { Guarantee disability and retirement } \\
\text { benefits are granted to those who have had } \\
\text { little or no income. }\end{array}$ & $\begin{array}{l}\text { Permanent DB are converted into } \\
\text { retirement benefits at age } 65 . \\
\text { Discontinuities in benefit levels are } \\
\text { likely to occur. }\end{array}$ \\
\hline Poland & $\begin{array}{l}\text { Defined Benefit formula for calculating } \\
\text { benefits, based on the length of the contributory } \\
\text { and non-contributory periods, the general base } \\
\text { amount, the hypothetical carrier path and the } \\
\text { degree of disability. }\end{array}$ & $\begin{array}{l}\text { If the retirement pension is below the } \\
\text { minimum level, the pension is topped-up } \\
\text { by the minimum pension guarantee } \\
\text { (MPG), which is financed from the state } \\
\text { budget. The MPG is also in force for } \\
\text { permanent disability benefits. }\end{array}$ & $\begin{array}{l}\text { Replaced by retirement pensions for } \\
\text { beneficiaries who have reached the } \\
\text { statutory retirement age. In most } \\
\text { cases, their (retirement) benefits are } \\
\text { higher than those of individuals } \\
\text { retiring under the new NDC/FDC } \\
\text { system. }\end{array}$ \\
\hline Italy & $\begin{array}{l}\text { Defined contribution formula based on the } \\
\text { notional capital accumulated at the time of } \\
\text { disability plus a "contributory bonus" which } \\
\text { depends on the disability claimant's age and the } \\
\text { wages in the preceding five years before the } \\
\text { disability onset. The formula includes the } \\
\text { possibility of paying survivor benefits: }\end{array}$ & $\begin{array}{l}\text { Guaranteed minimum pension: Paid to } \\
\text { social insurance or mixed program } \\
\text { pensioners with a monthly pension lower } \\
\text { than the minimum living income. }\end{array}$ & There is no change. \\
\hline
\end{tabular}


Table 6: Disability, minimum (guaranteed) pension benefits and NDCs in practice: Summary (part 1)

\begin{tabular}{|c|c|c|c|}
\hline \multicolumn{4}{|c|}{ Table 6: Disability, minimum (guaranteed) pension benefits and NDCs in practice: Summary (part 1) } \\
\hline Countries/concepts & Disability formula & Minimum Pension/Guarantee & $\begin{array}{l}\text { Disability benefits (DB) } \\
\text { in the retirement period }\end{array}$ \\
\hline Latvia & $\begin{array}{l}\text { Disability benefits are determined by a defined } \\
\text { benefit formula, the amount of the benefits } \\
\text { depends on the degree of disability, the } \\
\text { contribution base for the preceding five years } \\
\text { before the disability occurs (the highest earnings } \\
\text { for three years in the previous } 5 \text { year period) and } \\
\text { the number of contributed years. }\end{array}$ & $\begin{array}{l}\text { The minimum monthly old-age pension } \\
\text { varies with the number of years } \\
\text { contributed to the system. The higher the } \\
\text { number of years insured the higher the } \\
\text { guaranteed benefit. }\end{array}$ & $\begin{array}{l}\text { Disability pensions are converted into } \\
\text { old age pensions according to NDC } \\
\text { rules, but the old-age pension cannot } \\
\text { be lower than the granted disability } \\
\text { benefit. }\end{array}$ \\
\hline Norway & $\begin{array}{l}\text { The disability benefit is equivalent to } 66 \text { percent } \\
\text { of the contribution base, based on the three } \\
\text { highest years for the preceding five years before } \\
\text { the affiliate becomes disabled. If a person has } \\
\text { not lost their entire earnings capacity, the } \\
\text { disability benefit is graded. }\end{array}$ & $\begin{array}{l}\text { If the individual has had low or no income, } \\
\text { she/he is entitled to a basic benefit. A } \\
\text { guaranteed pension of } 2 \text { basic pension } \\
\text { units (BPU) for singles and } 1.85 \text { BPU per } \\
\text { person for couples, secures a minimum } \\
\text { level of benefits for pensioners with low } \\
\text { labour incomes. BPU is a measurement } \\
\text { unit in the National Insurance Scheme } \\
\text { corresponding to about } 1 / 6 \text { of the average } \\
\text { annual wage level for a full-time } \\
\text { employee. }\end{array}$ & $\begin{array}{l}\text { After the age of } 67 \text {, anyone receiving } \\
\text { disability benefit will receive a } \\
\text { retirement pension instead. Disability } \\
\text { pensioners are partially exempted } \\
\text { from life age adjustments, so the } \\
\text { "system" gives incentives to become } \\
\text { disabled before obtaining the } \\
\text { retirement pension. }\end{array}$ \\
\hline \multicolumn{4}{|c|}{ Source: Own } \\
\hline
\end{tabular}




\section{APPENDIX 3.-TECHNICAL APPENDIX}

This technical appendix summarizes the basics of the theoretical model in the steady state and the main formulas used to build the actuarial balance.

The multiple state model used as a basis, $(\mathcal{S}, \mathcal{T})$, is a non-homogeneous multi-state discrete time Markov process, $\left\{S(t), t \in \mathbb{Z}^{+}\right\}$, where $S(t)$ is the random variable that represents the process state at time $t$ with values in the finite state space, $\mathcal{S}=\{a, r, d, f\}$, a set of four possible random events that represent statuses of the PAYGO scheme members, with just one state at any time: contributors (active) (a), retired (healthy) $(r)$, disabled $(d)$, and deceased $(f)$. The potential transitions between the states are described by a set of direct possible unidirectional ordered pairs $\mathcal{T}=$ $\{(a, r),(a, f),(a, d),(r, f),(d, f)\}$, whose associated transition probabilities depend only on the current state of the process (Ventura-Marco and Vidal-Meliá, 2014 and 2016). The above set up, combined with the standard double-entry bookkeeping method with mathematical demography, can be termed as a multiple overlapping generations model (MOLG).

Number of contributors by age at time $t: l_{\left(x_{e}+k, t\right)}=l_{\left(x_{e}, t\right)}{ }_{k}{ }_{k} p_{x_{e}}^{a a}$, in which ${ }_{k} p_{x_{e}}^{a a}$ is the probability that an active person aged $x_{e}+k$ years will reach age $x_{e}+k-1$ being active. This includes the decrements due to death and disability associated with each age $\left(x_{e}+k \in\left[x_{e}, x_{e}+A-1\right]\right)$ at time $t$, with no possibility of a return to active life being considered. It is a different matter when it comes to considering decrements involving the economically active population or new entries over time due to migratory movements. These are included in parameter $\gamma$, which is an annual accumulative rate.

Average wage (contribution base) at time $t: y_{\left(x_{e}+k, t\right)}=y_{\left(x_{e}+k, 1\right)} \cdot(1+g)^{t-1}$, i.e. the contribution base (coinciding with earnings) grows at an annual rate of $g$ affecting all groups of contributors. A concave income profile typical of developed countries is assumed. The age-wage structure only undergoes proportional changes. The slope of the age-wage structure is constant.

\section{Number of disabled people:}

For each age $x_{e}+k \in\left[x_{e}+1, x_{e}+A\right]$, the total number of disabled at time $t$ can be calculated by:

$$
l_{\left(x_{e}+k, t\right)}^{d}=\sum_{s=1}^{k} D_{\left(x_{e}+s, t-k+s\right)}{ }_{k-s} p_{x_{e}+s}^{d d}
$$

where $D_{\left(x_{e}+s, t\right)}=l_{\left(x_{e}+s-1, t-1\right)} \cdot p_{x_{e}+s-1}^{a d}$ is the new disabled pensioners for age $x_{e}+s$ in $t$, obtained as the product of active workers or contributors of age $x_{e}+s-1$ in previous time $t-1$ and the probability that an active person aged $x_{e}+s-1$ will become disabled during the year. ${ }_{k-s} p_{x_{e}+s}^{d d}$ is the probability that a disabled person aged $x_{e}+s$ will survive until age $x_{e}+k$ being disabled. The structure of the survivor disabled will depend on the survival probabilities $\left(p_{x_{e}+k}^{d d}\right)$, which are different from those for the active population $\left(p_{x_{e}+k}^{a a}\right)$ and incorporate all those who became disabled in successive earlier periods and have survived.

From age $x_{e}+A+1$ years onwards, no more new disabled people are taken into account because all the disabled in the system are considered by definition to be survivor disabled, and so for age interval $\left[x_{e}+A+1, w-1\right]$, i.e. $k \in\left\{1,2, \ldots, w-1-\left(x_{e}+A\right)\right\}$, we 
get:

$$
l_{\left(x_{e}+A+k, t\right)}^{d}=l_{\left(x_{e}+A, t-k\right)}^{d}{ }_{k} p_{x_{e}+A}^{d d}=\left(\sum_{s=1}^{A} D_{\left(x_{e}+s, t-k+s-A\right){ }^{*}{ }_{A-s}} p_{x_{e}+s}^{d d}\right){ }_{k} p_{x_{e}+A}^{d d}
$$

There are $k \in\{1,2, \ldots, A\}$ different contribution pathways that will determine $k$ different pensions, as contributors might be working for 1 year, 2 years..., $k$ years. For $c=k$, these pensions would be for people with a full contribution history, i.e. those who enter the labour market at the earliest age $\left(x_{e}\right)$ and exit aged $x_{e}+k-1$ for disability

$$
l_{\left(x_{e}+k, t\right)}=\sum_{c=1}^{k} l_{\left(x_{e}+k, c, t\right)}
$$

and $x_{e}+A$ years for retirement,

$$
l_{\left(x_{e}+A, t\right)}=\sum_{c=1}^{A} l_{\left(x_{e}+A, c, t\right)}
$$

\section{Determining the Average Initial Pension in a Pure NDC Scheme:}

\section{- Disability}

The pure NDC average pension for disabled individuals at age $x_{e}+k$, with $k \in\{1,2, \ldots, A\}$, computed as a weighted pension of the $k$ different disability pensions once settled, $c \in\{1, \ldots, k\}$, is:

where

$$
\bar{P}_{\left(x_{e}+k, t\right)}^{N D C[D]}=\frac{\sum_{c=1}^{k} P_{\left(x_{e}+k, c, t\right)}^{N D C[D]} \cdot D_{\left(x_{e}+k, c, t\right)}}{D_{\left(x_{e}+k, t\right)}}
$$

$P_{\left(x_{e}+k, c, t\right)}^{N D C[D]}$ is the initial disability pension awarded using the NDC formula,

$$
P_{\left(x_{e}+k, c, t\right)}^{N D C[D]}=\frac{\left(K_{\left(x_{e}+k-1, c-1, t-1\right)}^{a c}+\theta_{a} \cdot y_{\left(x_{e}+k-1, t-1\right)}\right) \cdot(1+G)}{\alpha \ddot{a}_{x_{e}+k}^{d}}
$$

with $K_{\left(x_{e}+k-1, c-1, t-1\right)}^{a c}$ as the cumulated notional capital (or pension balance) at time $t-$ 1 for one individual aged $x_{e}+k-1$ who has been contributing for the last $c-1$ years. It is obvious that

$$
\bar{K}_{\left(x_{e}+k-1, t-1\right)}^{a c}=\frac{\sum_{c=1}^{k} K_{\left(x_{e}+k-1, c-1, t-1\right)}^{a c} \cdot D_{\left(x_{e}+k, c, t\right)}}{D_{\left(x_{e}+k, t\right)}}
$$

$\theta_{a}$ is the credited contribution rate;

${ }^{\alpha} \ddot{a}_{x_{e}+k}^{d}$ is the annuity factor: $A f^{D}$, i.e. the present value of a lifetime annuity for the disabled of 1 monetary unit per year payable in advance and growing at real rate $\alpha$, valued 
at age $x_{e}+k$ years and with a technical interest rate equal to $G$, the wage bill growth (The rate of return of the model in equilibrium).

The system's income from contributions also grows (decreases) at rate $G=(1+g)(1+$ $\gamma)-1$, where the contribution base grows at an annual rate of $g$ and the economically active population increases or decreases over time at an annual accumulative rate of $\gamma$, affecting all groups of contributors equally.

The total accumulated notional capital in year $t$ for the generation aged $x_{e}+k$, $k \in\{1, \ldots, A\}$, can be expressed as:

$$
\begin{gathered}
K_{\left(x_{e}+k, t\right)}^{T a c}=\sum_{c=1}^{k} K_{\left(x_{e}+k, c, t\right)}^{a c} \cdot l_{\left(x_{e}+k, c, t\right)} \\
\left(K_{\left(x_{e}+k-1, t-1\right)}^{T a c}+\theta_{a} \cdot y_{\left(x_{e}+k-1, t-1\right)} \cdot l_{\left(x_{e}+k-1, t-1\right)}\right) \cdot(1+G) \cdot\left(1-p_{x_{e}+k-1}^{a d}\right) \\
= \\
\theta_{a} \cdot\left[\sum_{s=0}^{k-1} y_{\left(x_{e}+s, t\right)} \cdot l_{\left(x_{e}+s, t\right)} \cdot\left[\prod_{h=s}^{k-1}\left(p_{x_{e}+h}^{a a}+p_{x_{e}+h}^{a d}\right)\right]\right]
\end{gathered}
$$

where $p_{x_{e}+h}^{a d}$ is the probability that an active person aged $x_{e}+h$ will become disabled during the year.

If we include contributions made in year $t$ for the generation aged $x_{e}+k$ years and take into account formula [15.], we get $K_{\left(x_{e}+k, t\right)}^{T a c+]}=K_{\left(x_{e}+k, t\right)}^{T a c}+\theta_{a} \cdot y_{\left(x_{e}+k, t\right)} \cdot l_{\left(x_{e}+k, t\right)}$. Hence with the total accumulated notional capital in year $t$ for the generation aged $x_{e}+k$, and with contributions for time $t$ being included at age $x_{e}+k \in\left\{x_{e}+1, \ldots, x_{e}+A-1\right\}$ for all contributors who reach that age,

\section{- Retirement}

The pure NDC average pension for retirement at age $x_{e}+A$, computed as a weighted pension of the $k$ different disability pensions once settled, $c \in\{1, \ldots, A\}$, is:

$$
\bar{P}_{\left(x_{e}+A, t\right)}^{N D C[R]}=\frac{\sum_{c=1}^{A} P_{\left(x_{e}+A, c, t\right)}^{N D C[R]} \cdot l_{\left(x_{e}+A, c, t\right)}}{l_{\left(x_{e}+A, t\right)}}=\frac{\bar{K}_{\left(x_{e}+A, t\right)}^{a c}}{{ }^{\alpha} \ddot{a}_{x_{e}+A}^{r}}
$$

Where, $P_{\left(x_{e}+k, c, t\right)}^{N D C[R]}$ the initial retirement pension awarded using the NDC formula.

${ }^{\alpha} \ddot{a}_{x_{e}+A}^{r}$ is the annuity factor: $A f^{R}$, i.e. the present value of a lifetime annuity for the retired of 1 monetary unit per year payable in advance and growing at real rate $\alpha$, valued at age $x_{e}+A$ years and with a technical interest rate equal to $G$.

$\bar{K}_{\left(x_{e}+A, t\right)}^{a c}$ is the total average accumulated notional capital or pension balance at age $x_{e}+$ A: 


$$
\bar{K}_{\left(x_{e}+A, t\right)}^{a c}=\frac{\overbrace{\theta_{a} \cdot\left[\sum_{s=0}^{A-1} y_{\left(x_{e}+s, t\right)} \cdot l_{\left(x_{e}+s, t\right)} \cdot\left[\prod_{h=s}^{A-1}\left(p_{x_{e}+h}^{a a}+p_{x_{e}+h}^{a d}\right)\right]\right]}^{K_{\left(x_{e}+A, t\right)}^{T a c}}}{l_{\left(x_{e}+A, t\right)}}
$$

and $K_{\left(x_{e}+A, t\right)}^{T a c}$ is the total accumulated notional capital at time $\mathrm{t}$ for all individual contributors who reach age $x_{e}+A$, it can also be expressed as:

$$
K_{\left(x_{e}+A, t\right)}^{T a c}=\theta_{a} \cdot \sum_{k=0}^{A-1} l_{\left(x_{e}+k, k+t-A\right)} \cdot \overbrace{y_{\left(x_{e}+k, k+t-A\right)}}^{\text {The average wage (contribution base) }} \cdot(1+G)^{A-k}
$$

\section{Determining the Average Initial Pension with a Minimum Pension Benefit}

\section{- Disability}

The average pension for disabled individuals at age $x_{e}+k$, with $k \in\{1,2, \ldots, A\}$, computed as a weighted pension of the $k$ different disability pensions once settled, $c \in\{1, \ldots, k\}$, is:

$$
\bar{P}_{\left(x_{e}+k, t\right)}^{D}=\frac{\sum_{c=1}^{k} P_{\left(x_{e}+k, c, t\right)}^{D} \cdot D_{\left(x_{e}+k, c, t\right)}}{D_{\left(x_{e}+k, t\right)}}=\bar{P}_{\left(x_{e}+k, t\right)}^{N D C[D]}+\overline{S P}_{\left(x_{e}+k, t\right)}^{D}
$$

where

$P_{\left(x_{e}+k, c, t\right)}^{D}=\operatorname{Max}\left\{P_{\left(x_{e}+k, c, t\right)}^{N D C[D]}, P_{(\Omega, t)}^{M I N}\right\}$ is the amount of the effective initial pension income for disability paid at age $x_{e}+k$ with $k \in\{1, \ldots, A\}$ and with $c \in\{1, \ldots, k\}$ years of contributions recorded, with $P_{(\Omega, t)}^{M I N}$ as the minimum (disability) pension and $P_{\left(x_{e}+k, c, t\right)}^{N D C[D]}$ the initial disability pension awarded using the NDC formula.

$\overline{S P}_{\left(x_{e}+k, t\right)}^{D}$ is the average supplementary disability benefit for age $x_{e}+k$, defined as:

$$
\overline{S P}\left(x_{e}+k, t\right)=\frac{\sum_{c=1}^{k} \operatorname{Max}\left\{P_{(\Omega, t)}^{M I N}-P_{\left(x_{e}+k, c, t\right)}^{N D C[D]}, 0\right\} \cdot D_{\left(x_{e}+k, c, t\right)}}{D_{\left(x_{e}+k, t\right)}}
$$

Under the assumption that all pensions are indexed at the same rate $(\alpha)$, we can define the difference between the present value of the positive differences between the minimum pensions awarded and the account balances of participants available at the time of the disability $(t)$ for age $x_{e}+k$ by

$$
\overline{V S P}_{\left(x_{e}+k, t\right)}^{D}=\overline{S P}_{\left(x_{e}+k, t\right)}^{D} \cdot{ }^{\alpha} \ddot{a}_{x_{e}+k}^{d}
$$

\section{- Retirement}

The average pension for individuals who retire at the ordinary retirement age, computed as a weighted pension of the $A$ different retirement pensions once settled, $c \in\{1, \ldots, A\}$, is: 


$$
\bar{P}_{\left(x_{e}+A, t\right)}^{R}=\frac{\sum_{c=1}^{A} P_{\left(x_{e}+A, c, t\right)}^{R} \cdot l_{\left(x_{e}+A, c, t\right)}}{l_{\left(x_{e}+A, t\right)}}=\frac{\bar{K}_{\left(x_{e}+A, t\right)}^{a c}}{\alpha \ddot{a}_{x_{e}+A}^{r}}+\overline{S P}_{\left(x_{e}+A, t\right)}^{R}
$$

where $P_{\left(x_{e}+A, c, t\right)}^{R}=\operatorname{Max}\left\{P_{(\Omega, t)}^{M I N}, P_{\left(x_{e}+A, c, t\right)}^{N D C[R]}\right\}$ is the initial benefit awarded at retirement age, with

$P_{(\Omega, t)}^{M I N}$ : For simplicity, with the additional assumption that there is a common MPB for both contingencies.

The average supplementary retirement benefit at time $t$ is defined as:

$$
\overline{S P}_{\left(x_{e}+A, t\right)}^{R}=\frac{\sum_{c=1}^{A} \operatorname{Max}\left\{P_{(\Omega, t)}^{M I N}-P_{\left(x_{e}+A, c, t\right)}^{N D C[R]}, 0\right\} \cdot l_{\left(x_{e}+A, c, t\right)}}{l_{\left(x_{e}+A, t\right)}}=\frac{\overline{V S P}_{\left(x_{e}+A, t\right)}^{R}}{\alpha \ddot{a}_{x_{e}+A}^{r}}
$$

with

$\overline{V S P}_{\left(x_{e}+A, t\right)}^{R}=\overline{S P}_{\left(x_{e}+A, t\right)}^{R} \cdot{ }^{\alpha} \ddot{a}_{x_{e}+A}^{r}$ having the same meaning as $\overline{V S P}_{\left(x_{e}+k, t\right)}^{D}$ but for the retirement contingency at age $x_{e}+A$.

In short, the main way in which this differs from a pure NDC scheme (Ventura-Marco and Vidal-Meliá, 2016) is that, if the amount of the initial disability and retirement pensions is below a minimum value, the amount is supplemented up to the minimum benefit. The minimum pension guarantee requires that the government pay an amount equivalent to the difference between the accumulated notional pension account at time of retirement and the amount that would provide an annuity equivalent to the MPB.

\section{The liabilities side}

The actuarial accounting proposal splits the system into two parts: the actuarial part (pure NDC) and the redistributive part, which includes the assets and liabilities originating from non-contributory rights (NCRs).

\section{A) The actuarial part (NDC)}

\section{Liability to current pensioners for retirement contingency}

For the retirement contingency, the NDC liability to pensioners is equal to:

$$
{ }^{N D C[R]} V_{t}^{r}=\bar{P}_{\left(x_{e}+A, t\right)}^{N D C[R]} \cdot \sum_{k=0}^{w-1-\left(x_{e}+A\right)} l_{\left(x_{e}+A+k, t\right)} \cdot F^{k} \cdot{ }^{\alpha} \ddot{a}_{x_{e}+A+k}^{r}
$$

where $F=\frac{1+\alpha}{1+G}$ is an indexation factor which depends on $\alpha$ and $G$.

\section{Liability to current pensioners for disability}

For disability contingency, the NDC liability to pensioners can be expressed as: 


$$
\begin{aligned}
& { }^{N D C[D]} V_{t}^{r}=\sum_{k=1}^{A}\left(\sum_{s=1}^{k} \bar{P}_{\left(x_{e}+s, t\right)}^{N D C[D]} \cdot D_{\left(x_{e}+s, t\right)} \cdot F^{k-s}{ }_{k-s} p_{x_{e}+s}^{d d}\right) \cdot{ }^{\alpha} \ddot{a}_{x_{e}+k}^{d} \\
& + \\
& \sum_{k=1}^{w-\left(x_{e}+A\right)}\left(\sum_{s=1}^{A} \bar{P}_{\left(x_{e}+s, t\right)}^{N D C[D]} \cdot D_{\left(x_{e}+s, t\right)} \cdot F^{A+k-s}{ }_{A+k-s} p_{x_{e}+s}^{d d}\right) \cdot{ }^{\alpha} \ddot{a}_{x_{e}+A+k}^{d} \\
& = \\
& \overbrace{\sum_{k=1}^{A} \overline{\bar{P}}_{\left(x_{e}+k, t\right)}^{N D C[D]} \cdot l_{\left(x_{e}+k, t\right)}^{d} \cdot{ }^{\alpha} \ddot{a}_{x_{e}+k}^{d}}^{\sum_{\sum_{k=1}^{w-\left(x_{e}+A\right)} \overline{\bar{P}}_{\left(x_{e}+A+k, t\right)}^{N D C[D]} \cdot l_{\left(x_{e}+A+k, t\right)}^{d} \cdot{ }^{\alpha} \ddot{a}_{x_{e}+A+k}^{d}}^{\sum_{\text {Retirement period }}}}
\end{aligned}
$$

where

$\overline{\bar{P}}_{\left(x_{e}+k, t\right)}^{N D C[D]}$ is the average pension for disabled individuals at age $x_{e}+k$, for which disability occurred $k-s$ periods before, that is:

$$
\overline{\bar{P}}_{\left(x_{e}+k, t\right)}^{N D C[D]}=\frac{\sum_{s=1}^{k} \bar{P}_{\left(x_{e}+s, t\right)}^{N D C[D]} \cdot D_{\left(x_{e}+s, t\right)}{ }_{k-s} p_{x_{e}+s}^{d d}}{l_{\left(x_{e}+k, t\right)}^{d}}
$$

Likewise, it can be defined $\overline{\bar{P}}_{\left(x_{e}+A+k, t\right)}^{N D C[D]}$.

\section{Liability to current contributors for retirement}

The NDC liability to contributors for retirement is equal to:

$$
\begin{aligned}
& { }^{N D C[R]} V_{t}^{c}=\sum_{k=1}^{A} K_{\left(x_{e}+k, t\right)}^{T a c(R)} \\
& = \\
& \theta_{a} \cdot\left(\sum_{k=0}^{A-1} \sum_{s=0}^{k-1} l_{\left(x_{e}+s, t\right)} \cdot y_{\left(x_{e}+s, t\right)} \cdot\left[\prod_{h=s}^{k-1}\left(p_{x_{e}+h}^{a a}+p_{x_{e}+h}^{a d}\right)\right]\right) \\
& = \\
& \text { contribution rate } \\
& \text { for retirement } \\
& \widetilde{\theta}^{\text {etirement }} \cdot\left(\sum_{k=1}^{A} \sum_{s=0}^{k-1} l_{\left(x_{e}+s, t\right)} \cdot y_{\left(x_{e}+s, t\right)}\right)
\end{aligned}
$$

This liability is calculated using the notional philosophy, i.e. the liability to contributors is the sum of the pension balances allocated to retirement of all active contributors (past service liability for active members).

\section{Liability to current contributors for disability}

The NDC liability to contributors for disability is:

$$
{ }^{N D C[D]} V_{t}^{c}=\sum_{k=1}^{A} K_{\left(x_{e}+k, t\right)}^{T a c(D)}
$$




$$
\begin{aligned}
& \begin{array}{c}
= \\
\left(\sum_{k=1}^{A}\left(K_{\left(x_{e}+k-1, t-1\right)}^{T a c}+\theta_{a} \cdot l_{\left(x_{e}+k-1, t-1\right)} \cdot y_{\left(x_{e}+k-1, t-1\right)}\right) \cdot(1+G) \cdot p_{x_{e}+k-1}^{a i}\right)
\end{array} \\
& \text { contribution rate } \\
& \text { for disability } \\
& \overbrace{\theta^{D}}^{\text {disability }} \cdot\left(\sum_{k=1}^{A} \sum_{s=0}^{k-1} l_{\left(x_{e}+s, t\right)} \cdot y_{\left(x_{e}+s, t\right)}\right)
\end{aligned}
$$

\section{B) The redistributive part (NCR)}

\section{NCR liability to pensioners for retirement}

$$
\begin{aligned}
& { }^{N C R[R]} V_{t}^{r}=\sum_{k=0}^{w-\left(x_{e}+A\right)} \underbrace{\overline{S P}_{\left(x_{e}+A+k, t\right)}^{R} \cdot{ }^{\alpha} \ddot{a}_{x_{e}+A+k}^{r}}_{\overline{V S P}_{\left(x_{e}+A+k, t\right)}^{R}} \cdot l_{\left(x_{e}+A+k, t\right)} \\
& =
\end{aligned}
$$

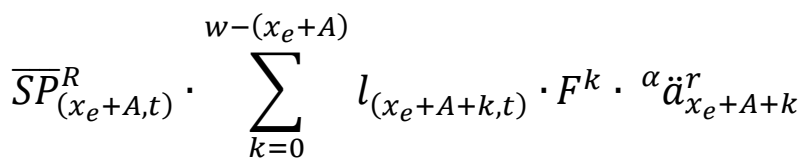

\section{NCR liability to pensioners for disability}

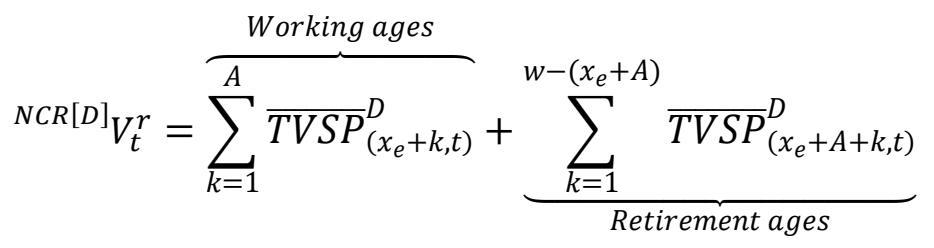

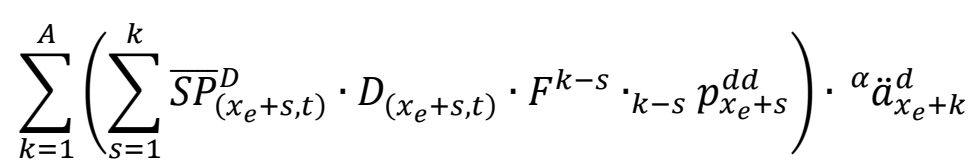

$$
\begin{aligned}
& \sum_{k=1}^{w-\left(x_{e}+A\right)}\left(\sum_{s=1}^{A} \overline{S P_{\left(x_{e}+s, t\right)}^{D}} \cdot D_{\left(x_{e}+s, t\right)} \cdot F^{A+k-s}{ }_{A+k-s} p_{x_{e}+s}^{d d}\right) \cdot{ }^{\alpha} \ddot{a}_{x_{e}+A+k}^{d}
\end{aligned}
$$

Where, the present value of the supplementary benefit for the group of disabled people aged $x_{e}+s$ can be expressed as:

$$
\overline{V S P}_{\left(x_{e}+s, t\right)}^{D} \cdot D_{\left(x_{e}+s, t\right)}=\overline{S P}_{\left(x_{e}+s, t\right)}^{D} \cdot D_{\left(x_{e}+s, t\right)} \cdot{ }^{\alpha} \ddot{a}_{x_{e}+s}^{d}
$$

Similarly, the present value of the supplementary benefit for the total disabled pensioners in the working ages:

$$
\overline{\operatorname{TVSP}}_{\left(x_{e}+k, t\right)}^{D}=\sum_{s=1}^{k} \overline{\operatorname{VPP}}_{\left(x_{e}+s, t\right)}^{D} \cdot D_{\left(x_{e}+s, t\right)}
$$

Likewise, the present value of the supplementary benefit for the total disabled pensioners in the retirement ages can be expressed as:

$$
\overline{\operatorname{TVSP}}_{\left(x_{e}+A+k, t\right)}^{D}=\sum_{s=1}^{A} \overline{\operatorname{VPP}}_{\left(x_{e}+s, t\right)}^{D} \cdot D_{\left(x_{e}+s, t\right)}
$$


Being, the average supplementary benefit for disabled people at age $x_{e}+k$ :

$$
\overline{S P}\left(x_{e}+k, t\right)=\frac{\sum_{c=1}^{k} \operatorname{Max}\left\{P_{(\Omega, t)}^{M I N}-P_{\left(x_{e}+k, c, t\right)}^{N D C[D]}, 0\right\} \cdot D_{\left(x_{e}+k, c, t\right)}}{D_{\left(x_{e}+k, t\right)}}
$$

\section{NCR liability to contributors for retirement and disability}

If the "Swedish" principle were applied, the liability to contributors for retirement and disability due to the NCRs should be zero.

Instead, if it were to break the principle of not making explicit projections, by taking into account the future wage development, the inclusion of a MPB would imply the valuation of the accrued minimum benefit by means of the prospective measure by the forecasted method. Obviously this amount, $V_{t}^{c}$, will be higher than the sum of the pension balances of active contributors, ${ }^{N D C} V_{t}^{c}$, being the difference in the liability to contributors for retirement and disability.

For retirement:

$$
\begin{aligned}
& { }^{N C R}[R] V_{t}^{c} \\
& = \\
& { }^{[R]} V_{t}^{c} \\
& \text { Present value of future contributions } \\
& \text { for retirement } \\
& \underbrace{\theta^{R} \cdot\left(\sum_{k=0}^{A-1} \sum_{s=0}^{k} l_{\left(x_{e}+k, t\right)} \cdot y_{\left(x_{e}+k, t\right)} \cdot F^{* h}\right)}_{\bar{P}_{\left(x_{e}+A, t\right)}^{R} \cdot l_{\left(x_{e}+A, t\right)} \cdot{ }^{\alpha} \ddot{a}_{x_{e}+A}^{r} \cdot \sum_{h=1}^{A} F^{* h}} \\
& \text { Present value of retirement benefits } \\
& \stackrel{-}{N D C[R]} V_{t}^{c} \\
& \sum_{k=1}^{A} K_{\left(x_{e}+k, t\right)}^{T a c(R)} \\
& \text { Accumulated notional capital for retirement }
\end{aligned}
$$

Being $F^{*}=\frac{1+G}{1+d}$ an indexing factor.

Anagously, for disability:

$$
\begin{gathered}
{ }^{N C R[D]} V_{t}^{c}={ }^{D} V_{t}^{c}-{ }^{N D C[D]} V_{t}^{c} \\
= \\
\underbrace{\sum_{k=1}^{A} \bar{P}_{\left(x_{e}+k, t\right)}^{D} \cdot D_{\left(x_{e}+k, t\right)} \cdot{ }^{\alpha} \ddot{a}_{x_{e}+k}^{d} \cdot \sum_{h=1}^{A} F^{* h}}_{\text {Present value of disability benefits }} \\
\underbrace{\theta^{D}\left(\sum_{k=0}^{A-1} \sum_{s=0}^{k} l_{\left(x_{e}+k, t\right)} \cdot y_{\left(x_{e}+k, t\right)} \cdot F^{* h}\right)}_{\text {Present value of future contributions for disability }}
\end{gathered}
$$




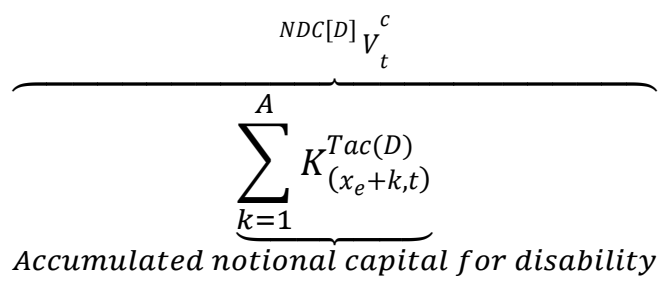

\section{The assets side and the steady state balance ratio.}

The system's contribution asset $\left({ }^{N D C} C A_{t}^{S}\right)$ can be understood as the maximum level of liabilities $\left({ }^{N D C} V_{t}^{S}\right)$ that can be financed by the contribution rate.

A different question is the redistributive element of the scheme, i.e. the commitments to pensioners and contributors to cover NCR rights. In our proposal the counterpart on the assets side is the buffer fund allocated to back up the non-contributory rights ( ${ }^{N C R} B F_{t}^{S}$ ) that should be financed from general revenues. Therefore,

$$
\overbrace{{ }^{N D C} C A_{t}^{S}+{ }^{N C R} B F_{t}^{S}}^{\text {Total assets }}=\underbrace{{ }^{N D C} V_{t}^{S}+{ }^{N C R} V_{t}^{S}}_{\text {Total liabilities }}
$$

The value of the system's contribution asset is the product of the system's turnover duration $\left(T D_{t}^{S}\right)$ and the value of the NDC system's contributions $\left(C_{t}^{S}\right)$ made in that period for the retirement and disability contingencies:

$$
{ }^{N D C} C A_{t}^{S}=T D_{t}^{S} \cdot C_{t}^{S}
$$

The $T D_{t}^{S}$ for the system is interpreted as the number of years expected to elapse before the committed liabilities with contributors (pay-in, $p t_{c}^{S}$ ) and pensioners (pay-out, $p t_{r}^{S}$ ) both retirement and disability contingencies are completely renewed at the current contribution level.

In the case of retirement, the $T D_{t}^{\boldsymbol{R}}$ indicates the expected years the contribution will stay in the system if it were paid by a hypothetical contributor of $A_{c}$ years and remained within the contribution liability until retirement age was reached (pay-in, $p t_{c}^{R}=A-A_{c}$ ), and was then received by a hypothetical able/healthy pensioner of $A_{r}^{R}$ years after remaining within the liability to this type of pensioners during the pay-out $\left(p t_{r}^{R}=A_{r}^{R}-A\right)$.

Similarly for the disability contingency, the $T D_{t}^{D}$ represents the expected years a monetary unit contributed to the system will stay in the system if it were paid by a contributor of $A_{C}$ years and remained within the liability to contributors until the affiliate became a disability recipient (pay-in, $p t_{c}^{D}$ ), and was then received by a disabled pensioner of $A_{r}^{D}$ years after remaining within the liability to this type of pensioners during the payout $\left(p t_{r}^{D}\right)$.

The system's turnover duration can be calculated as the weighted average of the $T D_{t}^{S}$ for both contingencies, disability $\left(T D_{t}^{D}\right)$ and retirement $\left(T D_{t}^{R}\right)$, with the weighting being the spending on pensions by contingency $\left(P T_{t}^{D}\right.$ and $\left.P T_{t}^{R}\right)$ as a part of total spending $\left(P T_{t}^{N D C}\right)$. Thus:

$$
T D_{t}^{S}=\frac{T D_{t}^{D} \cdot P T_{t}^{D}+T D_{t}^{R} \cdot P T_{t}^{R}}{P T_{t}^{N D C}}
$$


The system's turnover duration can also be calculated as the difference between the weighted average of the average ages of disability $\left(A_{r}^{D}\right)$ and retirement $\left(A_{r}^{R}\right)$, with the weightings here being spending on pensions per contingency as part of total spending and the average age of the contributors $\left(A_{C}^{D}=A_{C}^{R}=A_{C}\right)$. The analytical expression for the system's $T D$ can also be expressed in the form of pay-out and pay-in durations:

$$
T D_{t}^{S}=\frac{\overbrace{\left(A_{r}^{D}-A_{c}\right)}^{\left(p t_{c}^{D}+p t_{r}^{D}\right)} \cdot P T_{t}^{D}+\overbrace{\left(A_{r}^{R}-A_{c}\right)}^{\left(p t_{c}^{R}+p t_{r}^{R}\right)} \cdot P T_{t}^{R}}{P T_{t}^{N D C}}
$$

Finally, the impact of introducing the MPB on the (A)BS are the liabilities originated from NCRs, and this needs to have an equivalent entry on the assets side. In our proposal there are two entries, ${ }^{N C R} B F_{t}^{D}$ and ${ }^{N C R} B F_{t}^{R}$, and their amounts reveal the present value of the NCRs. Thus an NDC scheme providing an MPB becomes a special type of DB system (mixed o hybrid) and is partially funded in this approach.

The system's buffer fund $\left({ }^{N C R} B F_{t}{ }_{t}\right)$ that gives credibility and financial sustainability to the pensions promises made in the form of the MPB can be computed as follows:

$$
\begin{gathered}
{ }^{N C R} B F_{t}^{S}=V_{t}^{S}-{ }^{N D C} C A_{t}^{S} \\
= \\
\underbrace{{ }^{D} V_{t}^{r}+{ }^{D} V_{t}^{c}-{ }^{N D C} C A_{t}^{D}}_{{ }^{N C R} B F_{t}^{d}}+\overbrace{}^{{ }^{R} V_{t}^{r}+{ }^{R} V_{t}^{c}-{ }^{N D C} C A_{t}^{R}}
\end{gathered}
$$

and the amount of this is the present value of the public subsidies needed to finance the MPB.

It is also straightforward to obtain the value of the system's public contribution asset which is the product of the system's turnover duration $\left(T D_{t}^{S}\right)$ and the value of the NCR public contributions $\left({ }^{N C R} S P_{t}^{S}\right)$ made in that period by the sponsor in order to pay for the $M P B s$, and this is equivalent to the system's buffer fund:

$$
{ }^{N C R} C A_{t}^{S}=T D_{t}^{S} \cdot{ }^{N C R} S_{t}^{S}={ }^{N C R} B F_{t}^{S}
$$

If the approach adopted to back up the increase in liabilities due to the introduction of an MPB is the buffer fund method, the higher the level of the stipulated MPB, the higher the degree of funding $\left(D F_{t}^{S}\right)$ needed to maintain the system's financial equilibrium (shortterm sustainability). The degree of funding (level of funding) is the ratio between the amount of the buffer fund and the system's total liabilities:

$$
D F_{t}^{S}=\frac{{ }^{N C R} B F_{t}^{S}}{V_{t}^{S}}
$$

Finally, the sustainability indicator of the sytem called the steady state balance ratio $\left(B R_{t}^{S}\right.$, the ratio between the system's assets and liabilities) has to be equal to one in the case of a balanced pension system, our primary assumption. In our model, the balance ratio can be broken down by contingencies with the weightings here being the liabilities per contingency as part of total liabilities: 


$$
B R_{t}^{S}=B R_{t}^{R} \cdot \frac{\left({ }^{R} V_{t}^{r}+{ }^{R} V_{t}^{c}\right)}{V_{t}^{S}}+B R_{t}^{D} \cdot \frac{\left({ }^{D} V_{t}^{r}+{ }^{D} V_{t}^{c}\right)}{V_{t}^{S}}
$$

